\title{
Shigella evades pyroptosis by arginine ADP-riboxanation of caspase-11
}

https://doi.org/10.1038/s41586-021-04020-1

Received: 29 July 2020

Accepted: 14 September 2021

Published online: 20 October 2021

Check for updates

\section{Zilin $\mathrm{Li}^{1,2}$, Wang Liu ${ }^{1,2}$, Jiaqi $\mathrm{Fu}^{3}$, Sen Cheng ${ }^{2,3}$, Yue $\mathrm{Xu}^{1,2}$, Zhiqiang Wang ${ }^{2}$, Xiaofan Liu ${ }^{2}$, Xuyan Shi ${ }^{2}$, Yaxin Liư ${ }^{2}$, Xiangbing $\mathrm{Qi}^{2}$, Xiaoyun Liu ${ }^{3,4}{ }^{凶}$, Jingjin Ding ${ }^{2,5}$ \& Feng Shao ${ }^{1,2,5,6 \bowtie}$}

Mouse caspase- 11 and human caspase- 4 and caspase- 5 recognize cytosolic lipopolysaccharide (LPS) to induce pyroptosis by cleaving the pore-forming protein $\mathrm{GSDMD}^{1-5}$. This non-canonical inflammasome defends against Gram-negative bacteria ${ }^{6,7}$. Shigella flexneri, which causes bacillary dysentery, lives freely within the host cytosol where these caspases reside. However, the role of caspase-11mediated pyroptosis in S. flexneri infection is unknown. Here we show that caspase-11 did not protect mice from $S$. flexneri infection, in contrast to infection with another cytosolic bacterium, Burkholderia thailandensis ${ }^{8}$. S. flexneri evaded pyroptosis mediated by caspase-11 or caspase 4 (hereafter referred to as caspase-11/4) using a type III secretion system (T3SS) effector, OspC3. OspC3, but not its paralogues OspC1 and 2, covalently modified caspase-11/4; although it used the $\mathrm{NAD}^{+}$donor, this modification was not ADP-ribosylation. Biochemical dissections uncovered an ADPriboxanation modification on Arg314 and Arg310 in caspase-4 and caspase-11, respectively. The enzymatic activity was shared by $\mathrm{OspC} 1$ and 2 , whose ankyrin-repeat domains, unlike that of OspC3, could not recognize caspase-11/4. ADP-riboxanation of the arginine blocked autoprocessing of caspase- $4 / 11$ as well as their recognition and cleavage of GSDMD. ADP-riboxanation of caspase-11 paralysed pyroptosis-mediated defence in Shigella-infected mice and mutation of ospC3 stimulated caspase-11and GSDMD-dependent anti-Shigella humoral immunity, generating a vaccine-like protective effect. Our study establishes ADP-riboxanation of arginine as a bacterial virulence mechanism that prevents LPS-induced pyroptosis.
Intracellular S. flexneri infection causes shigellosis in humans. Although most intracellular bacteria reside in vacuoles, $S$. flexneri, like Burkholderia spp., live freely in the host cytosol, inevitably exposing their LPS to caspase-11/4. Wild-type (WT) mice, unlike Casp11 ${ }^{-/-}$ mice, survived B. thailandensis infection ${ }^{8}$ (Fig. 1a, Extended Data Fig. 1a). Mice are increasingly being used as a surrogate host for S. flexneri. Unexpectedly, both WT and Casp $11^{-/-}$mice succumbed to lethal S. flexneri infection (Fig. 1a) and tolerated similarly the low-dose challenge (Extended Data Fig. 1a). Given the absence of caspase-11-mediated protection, we assayed non-canonical inflammasome activation upon S. flexneri infection. Casp1 $1^{-1-}$ immortalized bone marrow-derived macrophages (iBMDMs) were used to avoid interference by the canonical inflammasome. Although $B$. thailandensis and S. Typhimurium $\Delta$ sifA induced Casp11-dependent GSDMD cleavage and pyroptosis ${ }^{8}$, S. flexneri triggered little pyroptosis (Fig. 1b) despite a higher infection efficiency (Extended Data Fig. 1b). In epithelium-derived human $\mathrm{SiHa}$ and $\mathrm{A} 431$ cells, S. flexneri, unlike $S$. Typhimurium $\Delta$ sifA, also did not activate the caspase-4-GSDMD pyroptosis pathway (Fig. 1b, Extended Data Fig. 1c, d). Purified LPS from S. flexneri was highly pro-pyroptotic (Extended Data Fig. 1e). Thus, $S$. flexneri evaded caspase-11/4-mediated pyroptosis.

The guanylate-binding protein (GBP) family promotes the release of LPS from intracellular bacteria and its presentation to caspase-11/4 (refs. ${ }^{9,10}$ ). IpaH9.8, a Shigella ubiquitin-ligase T3SS effector, targets multiple GBPs for degradation ${ }^{11-14}$. A 2013 report proposed that S. flexneri uses the T3SS effector OspC3 to target caspase-4 but, notably, not caspase-11 (ref. ${ }^{15}$ ). We examined whether IpaH9.8, OspC3 or another factor underlies evasion of pyroptosis by $\mathrm{S}$. flexneri using $\mathrm{SiHa}, \mathrm{A} 431$ and iBMDM cells (Fig.1c, Extended Data Fig.1d,f, g). Infection with $\Delta i p a H 9.8$, compared to WT bacteria, caused negligibly increased pyroptosis. By contrast, $\triangle o s p C 3$ induced extsensive pyroptosis with evident GSDMD cleavage, which was diminished by re-expression of OspC 3 in the bacteria or deletion of CASP4/11 deletion in the host cells. Deletion of all seven GBPs from A431 cells affected pyroptosis during early but not late infection (Extended Data Fig. 1h). This is consistent with the notion that GBPs, having little LPS-binding activity (Extended Data Fig. 1i), are not absolutely required for bacteria-induced caspase- 4 activation. Thus, S. flexneri requires OspC3 to evade LPS-stimulated pyroptosis.

${ }^{1}$ Research Unit of Pyroptosis and Immunity, Chinese Academy of Medical Sciences and National Institute of Biological Sciences, Beijing, China. ${ }^{2}$ National Institute of Biological Sciences, Beijing, China. ${ }^{3}$ Institute of Analytical Chemistry \& Synthetic and Functional Biomolecules Center, College of Chemistry and Molecular Engineering, Peking University, Beijing, China.

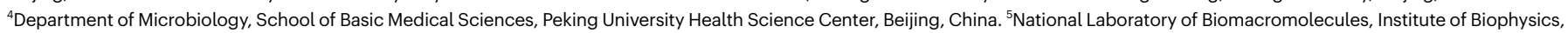

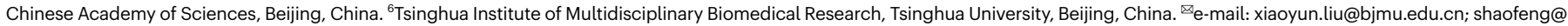
nibs.ac.cn 

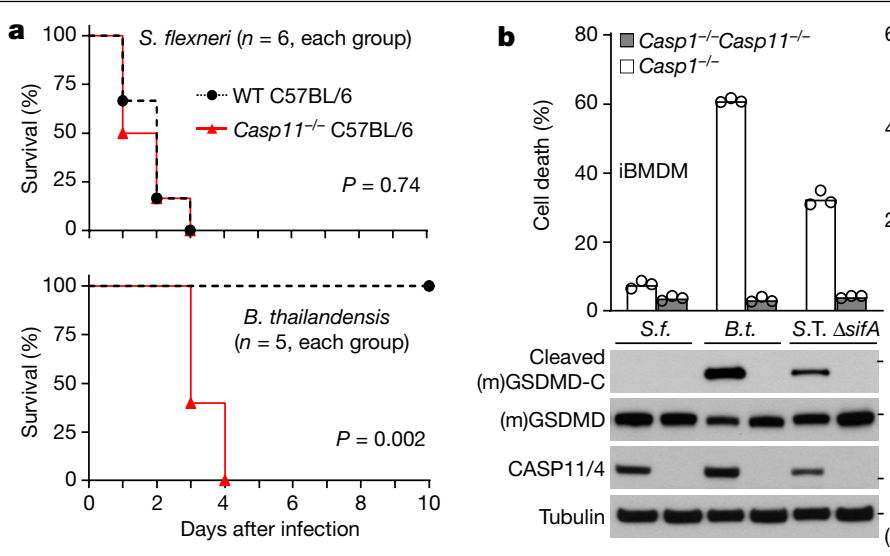

Fig. 1 |S. flexneriblocks cytosolic LPS-induced pyroptosis through OspC3. a, Survival curves of WT or Casp11 ${ }^{-/-}$mice intraperitoneally infected with S. flexneri or $B$. thailandensis $\left(2 \times 10^{7} \mathrm{CFU}\right.$ per mouse); two-tailed log-rank (Mantel-Cox) test.b,c, Indicated $\mathrm{SiH}$ a cells or iBMDMs were infected with S. flexneri (S.f., WT or an ospC3 deletion/complementation strain),

OspC3 expression in host cells blocked the induction of pyroptosis by S. flexneri $\Delta o s p C 3, S$. Typhimurium and even LPS alone (Extended Data Fig. 1j), suggesting that it has a bacteria-independent function. OspC3 co-immunoprecipitated with the p20/p10 form of caspase-4(C258A) (protease-deficient; C/A hereafter) in 293T cells (Extended Data Fig. 2a). The interaction did not cause $\mathrm{p} 20-\mathrm{p} 10$ dissociation, in contrast to earlier findings ${ }^{15}$. OspC3 also co-immunoprecipitated with inactive p20- and-p10-unprocessed caspase-4/11 (Fig. 2a, Extended Data Fig. 2b). OspC3 did not affect the proteolytic activity of caspase-4/11-p20/ p10 (Extended Data Fig. 2c-e). Purified OspC3 also did not inhibit LPS-induced activation of pro-caspase- 4 to cleave GSDMD, but it blocked pyroptosis when electroporated into cells (Extended Data Fig. 2f, g). Thus, hijacking of caspase-4/11 by OspC3 involves a cell-dependent mechanism.

In 293T cells, OspC3 induced slower migration of caspase-4-p10 on an SDS gel (Fig. 2b, Extended Data Fig. 2a). Caspase-4/11-p30, co-expressed with OspC3 in Escherichia coli, exhibited a marked shift on a native gel (Fig. 2c), indicating a post-translational modification (PTM). Electrospray ionization-mass spectrometry (ESI-MS) identified a 524-Da modification, which was located to ${ }_{314}$ RDSTMGSIF $_{322}$ within caspase-4-p10 by collision-induced dissociation (CID)-MS (Fig. 2d, Extended Data Fig. 2h, i). MS/MS detected fragment ions with mass-to-charge ratios of $136.06,348.07$ and 428.04 , matching the mass of adenine, AMP and ADP, respectively (Extended Data Fig. 2j). This reminded us of ADP-ribosylation, in which ADP-ribose (ADPR) from nicotinamide adenine dinucleotide $\left(\mathrm{NAD}^{+}\right)$is usually transferred to serine, arginine, asparagine, aspartate, glutamate or glutamine. Although the OspC3-induced PTM is 17 Da smaller than ADP-ribosylation, NAD ${ }^{+}$ enabled recombinant OspC3 to modify caspase-4/11-p30 by 524 Da (Fig. 2e, Extended Data Fig. $2 \mathrm{k}$, I). In S. flexneri infection, the ${ }_{314}$ RDSTMGSIF $_{322}$ peptide and the corresponding caspase-11 peptide showed the 524-Da modification in an ospC3-dependent manner (Extended Data Fig. $2 \mathrm{~m}$ ). Consistently, caspase-4-p30-C/A from cells infected with WT S. flexneri but not $\triangle o s p C 3$ had a mobility shift similar to that in the in vitro assay (Fig. 2f). Thus, OspC3 catalyses an $\mathrm{NAD}^{+}$-mediated PTM on caspase-4/11.

Electron-transfer/higher-energy collision dissociation (EThcD)MS showed that Arg314 and Arg310 in caspase-4 and -11, respectively, harboured the modification (Fig. 3a, Extended Data Fig. 3a). Replacing these residues with lysine or asparagine abolished the modification (Fig. 3b, Extended Data Fig. 3b-e). Quantitative high-performance liquid chromatography (HPLC)-MS analyses of the reaction (Extended Data Fig. 4a) revealed that one molecule of free nicotinamide (Nam)
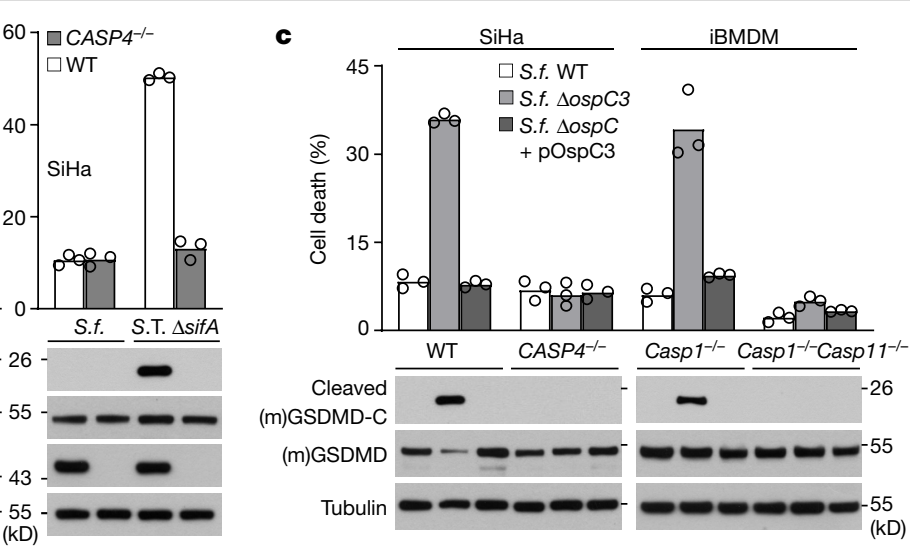

B. thailandensis (B.t.) or S. Typhimurium (S.T.) $\Delta$ sifA. LDH release-based cell death data are means (bars) of three individual replicates (circles). Cell supernatants were blotted with anti-cleaved GSDMD-C antibody. Data are representative of two (a) or three $(\mathbf{b}, \mathbf{c})$ independent experiments. For gel source data, see Supplementary Fig. 1.

was released upon modification of one molecule of caspase- 4 by one molecule of $\mathrm{NAD}^{+}$. Thus, the OspC3-catalysed PTM may contain an initial ADP-ribosylation and an additional 17-Da mass reduction reaction.

Fourteen $\mathrm{NAD}^{+}$analogues or derivatives were assayed in OspC 3 modification of caspase-4 (Extended Data Fig. 4b). NAD ${ }^{+}$fragments (ADPR, cyclic-ADPR (cADPR) and nicotinamide mononucleotide (NMN)), $\alpha-\mathrm{NAD}^{+}$, nicotinic acid adenine dinucleotide $\left(\mathrm{NAAD}^{+}\right)$, nicotinamide
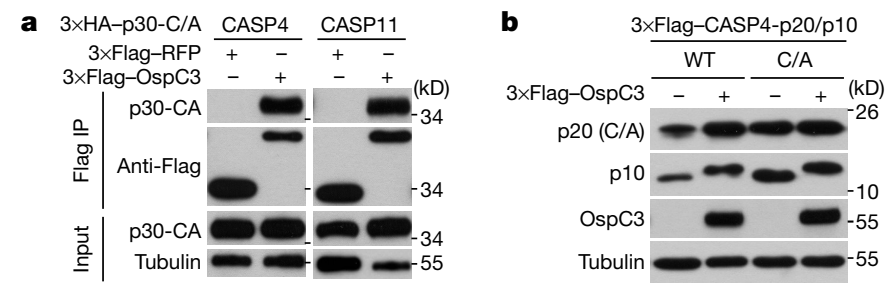

c
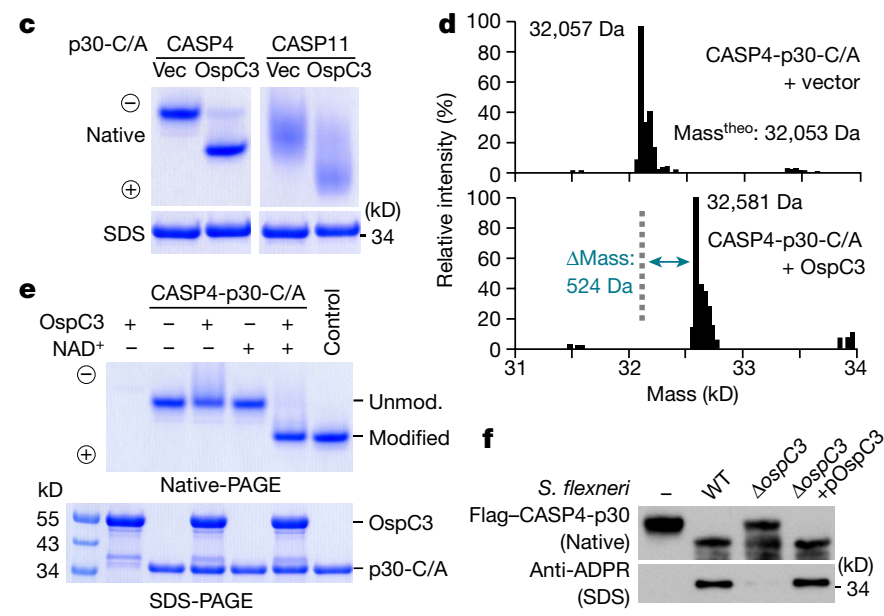

Fig. 2 | OspC3 catalyses an NAD ${ }^{+}$-dependent modification of caspase-4/11. a, b, Co-immunoprecipitation of caspase-4/11-p30-C/A with OspC3 and modification of caspase-4-p20/p10 by OspC3 in 293T cells. c-e, Caspase4/11-p30-C/A, expressed alone or with OspC3 in bacteria (c, d) or reacted with OspC 3 with or without $\mathrm{NAD}^{+}$in vitro $(\mathbf{e})$, was analysed by native/SDS-PAGE $(\mathbf{c}, \mathbf{e})$ or ESI-MS (d). Control, OspC3-modified caspase-4-p30-C/A.f, CASP4 ${ }^{-/-} \mathrm{HeLa}$ cells expressing Flag-caspase-4-p30-C/A were infected as indicated. Anti-Flag immunoprecipitates were analysed as shown. Data are representative of three $(\mathbf{a}-\mathbf{e})$ or two (f) independent experiments. For gel source data, see Supplementary Fig. 1 . 


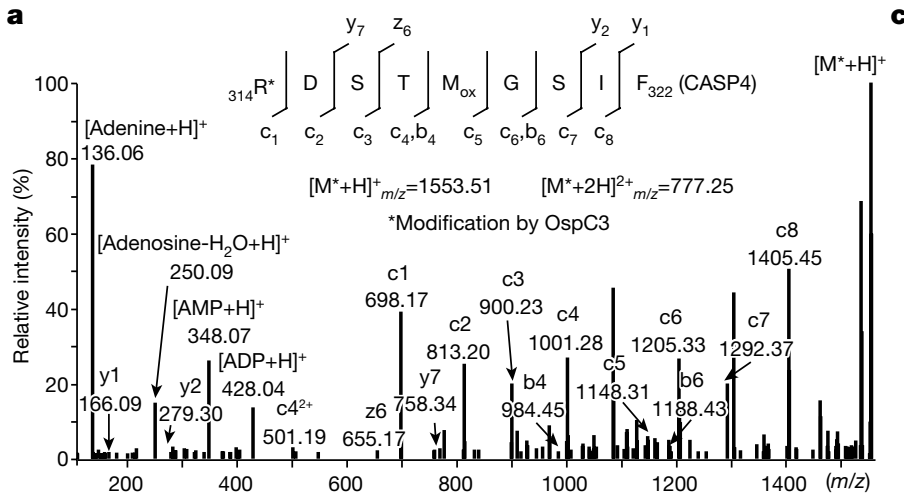

b

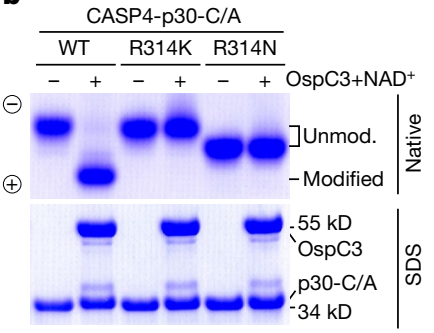

d

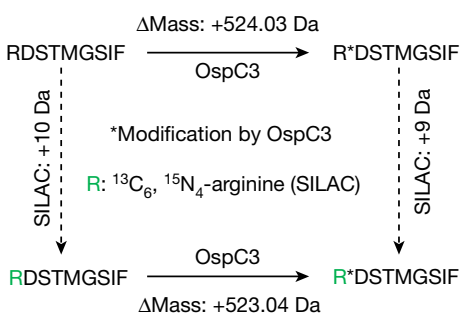

\begin{tabular}{|c|c|c|c|}
\hline \multicolumn{2}{|c|}{$\mathrm{NAD}^{+}$analogue } & Mass over & Modification \\
\hline \multicolumn{2}{|r|}{$\mathrm{NAD}^{+}$} & 0 & 524.03 \\
\hline \multirow{3}{*}{ 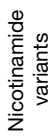 } & $\mathrm{NADH}$ & +1 & 524.03 \\
\hline & Thio-NAD ${ }^{+}$ & +16 & 524.03 \\
\hline & Thio-NADH & +17 & 524.03 \\
\hline \multirow{4}{*}{ 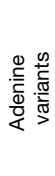 } & Deamino-NAD ${ }^{+}$ & +1 & 525.02 \\
\hline & $\varepsilon-\mathrm{NAD}^{+}$ & +24 & 548.03 \\
\hline & Biotin-NAD ${ }^{+}$ & +382.5 & 906.24 \\
\hline & $\mathrm{NGD}^{+}$ & +16 & 540.03 \\
\hline
\end{tabular}

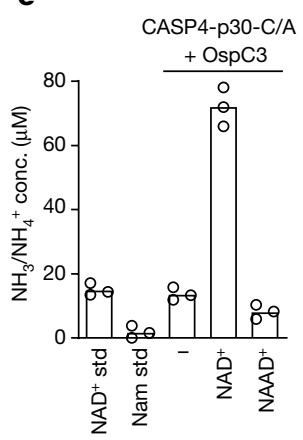

f - OspC3-

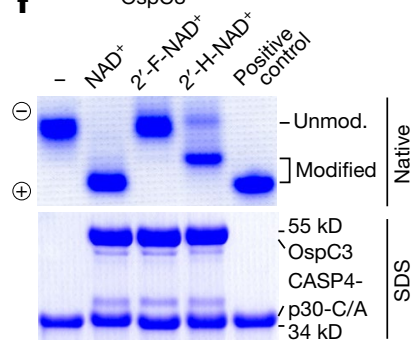

9
Fig. 3 | OspC3 catalyses ADP-riboxanation on an arginine in caspase-4/11. a, EThcD-tandem mass spectrum of the Arg314-containing peptide from OspC3-modified caspase-4-p30-C/A in bacteria. b, Caspase-4-p30-C/A was reacted with OspC3 with or without $\mathrm{NAD}^{+}$, followed by native/SDS-PAGE analyses. c, Mass changes of OspC3-modified caspase-4-p30 by NAD ${ }^{+}$ analogues. d, OspC3-induced mass changes on caspase-4 Arg314-containing peptide from normal or ${ }^{13} \mathrm{C}_{6},{ }^{15} \mathrm{~N}_{4}$-L-arginine-labelled 293T cells. e, Quantification of release of ammonia/ammonium from the OspC3modification reaction; data are means (bars) of three individual replicates (circles).f, Caspase-4-p30-C/A was reacted with OspC3 and a ribosyl $2^{\prime}$-substituted $\mathrm{NAD}^{+}$analogue. Control, OspC3-modified caspase-4-p30-C/A. g, Chemical structures of ADP-riboxanated and ADP-ribosylated arginine. Data are representative of three $(\mathbf{a}-\mathbf{c}, \mathbf{e}, \mathbf{f})$ or two $(\mathbf{d})$ independent experiments. For gel source data, see Supplementary Fig. 1 . adenine dinucleotide phosphate (NADP ${ }^{+}$) and NADPH were inactive. By contrast, $\mathrm{NADH}$, thio-NAD ${ }^{+}$and thio-NADH, altered in the Nam part, supported the 524-Da modification (Fig. 3c, Extended Data Fig. 4b, c). Deamino- $\mathrm{NAD}^{+}$, biotin-NAD ${ }^{+}, \varepsilon-\mathrm{NAD}^{+}$or nicotinamide guanine dinucleotide $\left(\mathrm{NGD}^{+}\right)$allowed modifications that preserved the mass difference between the cognate analogue and $\mathrm{NAD}^{+}$. These confirm the transfer of ADPR to caspase-4/11 with Nam being the leaving group. Indeed, OspC3-modified caspase-4 was recognized by an anti-ADP-ribose antibody ${ }^{16}$ (Fig. 2f, Extended Data Fig. 4d).

$\mathrm{NGD}^{+}$-mediated modification also had a 17-Da mass reduction from the 'GDP-ribosylation'. A non-specific pyrophosphohydrolase, NUDT16 (ref. ${ }^{17}$ ), removed an AMP from OspC3-modified caspase-4 (Extended Data Fig. 4d, e). These data suggest that the 17-Da loss occurs on the phosphoribosylated arginine. We performed stable isotope labelling by amino acids in cell culture (SILAC), using ${ }^{13} \mathrm{C}_{6},{ }^{15} \mathrm{~N}_{4}$-L-arginine to label Flagcaspase-4-p20/p10 expressed alone or with OspC3 in 293T cells. MS detected a 523-Da (not 524-Da) increase on a caspase- 4 Arg314-containing peptide (Fig. 3d, Extended Data Fig. 5a). The 1-Da change suggests that one $N^{\omega}$ atom in ADP-ribosylated arginine is removed via internal deamination, explaining the 17-Da reduction. Consistent with this, free $\mathrm{NH}_{3} / \mathrm{NH}_{4}{ }^{+}$was detected in the modification reaction (Fig. 3e).

The above analyses predict that a nucleophile adjacent to the ADP-ribosylated arginine guanidino performs the deamination. Studies of ADP-ribosylation-based elimination ${ }^{18}$ suggest that the ribosyl-2'-OH could be a candidate nucleophile. $\beta-2^{\prime}-$ Deoxy- $2^{\prime}-\mathrm{H}^{-\mathrm{NAD}^{+}}\left(2^{\prime}-\mathrm{H}^{-\mathrm{NAD}^{+}}\right)$ and $2^{\prime}$-fluoro-NAD ${ }^{+}$were assayed in the OspC3-catalysed modification (Extended Data Fig. 5b). 2'-Fluoro-NAD ${ }^{+}$, which is incompetent for canonical ADP-ribosylation ${ }^{19}$, could not support OpsC 3 modification

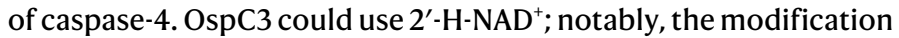
was merely the transfer of $2^{\prime}$-deoxy-ADPR without further deamination (Fig. 3f, Extended Data Fig. 5c). The remaining puzzle is the atom on which the initial ADP-ribosylation occurs. Both $N^{\omega}$ and $N^{\delta}$ in arginine can accept ADPR from $\mathrm{NAD}^{+}$. Ninhydrin could bond simultaneously with the two $N^{\omega}$ in native arginine, as noted with Arg314 in unmodified caspase- 4 (Extended Data Fig. 5d, e). For canonical arginine $N^{\omega}$-ADP-ribosylation (Rab4a by $\operatorname{ExoS}^{20}$ ), the modified arginine resisted conjugation by ninhydrin (Extended Data Fig. 5f). For 2'-H-NAD ${ }^{+}$-mediated modification, the 2'-deoxy-ADP-ribosylated Arg314 could react with ninhydrin (Extended Data Fig. 5e). We propose that OspC3 modifies Arg314/Arg310 of caspase-4/11 by two steps (Extended Data Fig. 5g). First, the arginine $N^{\delta}$ (rather than $N^{\omega}$ ) performs nucleophilic substitution of the Nam in $\mathrm{NAD}^{+}$. Second, the ribosyl-2'-OH of ADPR initiates a deamination to remove one $N^{\omega}$, forming an oxazolidine ring. We designate this arginine ADP-2'-imine-ribofurano[1', $\left.2^{\prime}: 4,5\right]$ oxazolidination modification as ADP-riboxanation (Fig. 3g), catalysed by arginine ADP-riboxanase activity in OspC3.

$S$. flexneri harbours ospC1, ospC2 and a pseudogene ospC4 in the $\operatorname{ospC} 3$ locus. OspC1, OspC2 and OspC3 (>60\% sequence identity; Extended Data Fig. 6a) share a C-terminal ankyrin-repeat domain (ARD) and an $\mathrm{N}$-terminal (N) domain (Fig. 4a). $\Delta$ ospC1 or $\Delta o s p C 2$ caused no increase in pyroptosis in infected cells (Extended Data Fig. 1f). OspC1/2 could not block cytosolic LPS-induced pyroptosis (Extended Data Fig. 6b). Purified OspC1/2 barely modified caspase- 4 (Fig. 4b). Notably, the ARD of OspC3, but neither OspC1/2 nor their ARDs, readily co-immunoprecipitated with caspase-4-p30 (Fig. 4c, Extended Data Fig. 6c). Replacing the ARD in OspC3 with that of OspC1/2 diminished its caspase-4-modification and pyroptosis-blocking activity (Fig. 4b, Extended Data Fig. 6b). Conversely, chimeric proteins with the OspC1/2 N-domain and OspC3 ARD were highly active. Thus, the ARD of OspC 3 determines caspase-4/11 recognition; OspC1/2 use their ARDs to target other host proteins for ADP-riboxanation.

Random mutagenesis identified Phe141, Phe186, Glu192, Glu326 and His328 in OspC3 (Fig. 4a, Extended Data Fig. 6a) as essential for 


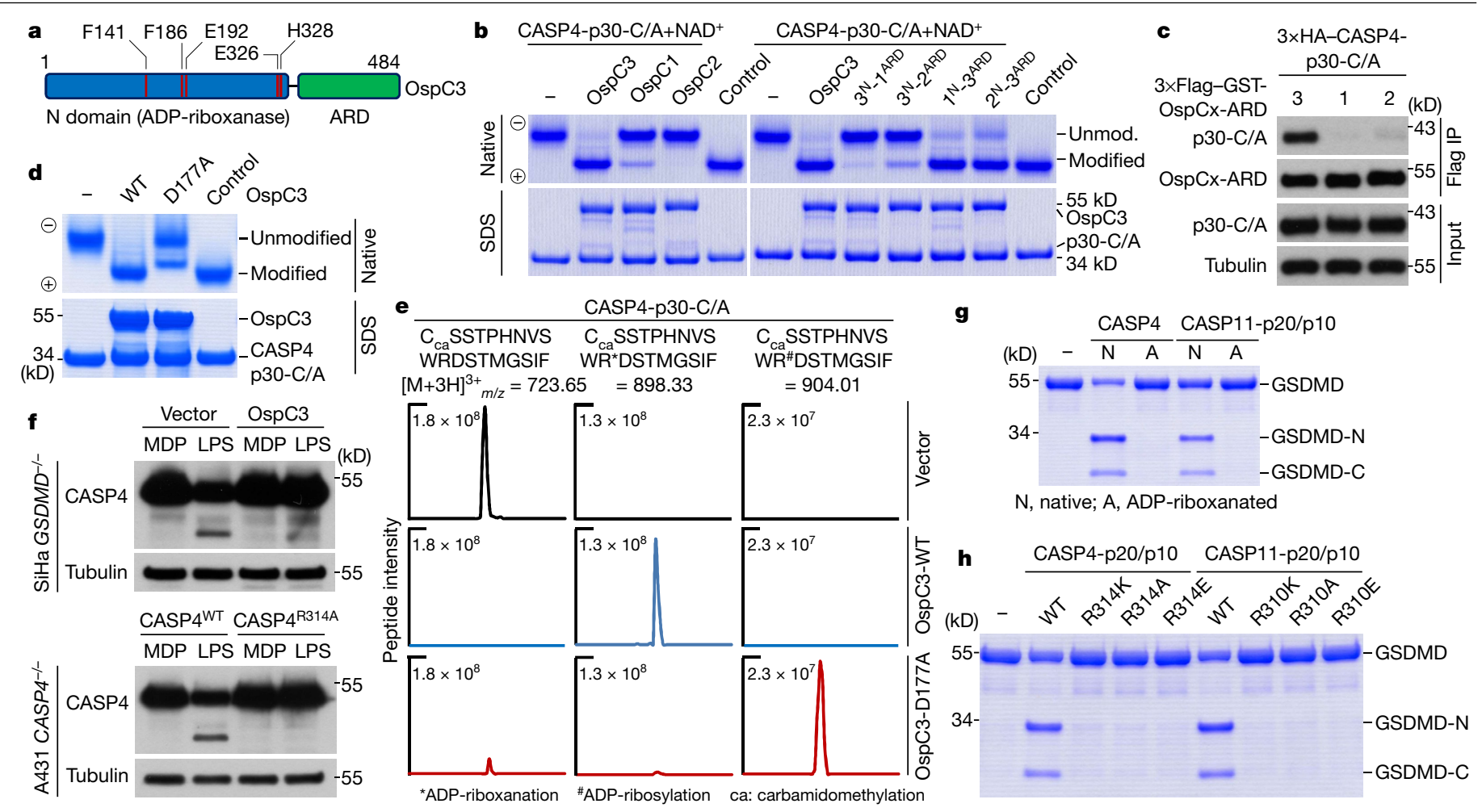

Fig. 4 | Analyses of the 0 spC family and mechanisms of $O$ spC 3 inactivation of caspase-4/11. a, Domain structure of OspC3 (red, residues essential for its ADP-riboxanase activity). b, Caspase-4-p30-C/A was reacted with OspC or a chimeric OspC protein, followed by native/SDS-PAGE analyses. c, Co-immunoprecipitation of caspase-4-p30-C/A with the ARD of an OspC in 293T cells. d, e, Caspase-4-p30-C/A modified by OspC3 (WT or D177A) in vitro (d) or in $E$. coli (e) was analysed by native/SDS-PAGE or MS, respectively.

ADP-riboxanating caspase-4/11 and blocking pyroptosis (Extended Data Fig. 6d-g). Another D177A mutation supported ADP-ribosylation but blocked subsequent deamination (Fig. 4d, e). Although OspC3(D177A)-modified caspase- 4 was sensitive to ADP-ribosylarginine hydrolase (ADPRH), WT OspC3-catalysed ADP-riboxanation resisted demodification by ADPRH and other known host ADP-ribosylhydrolases (Extended Data Fig. 6h, i). Thus, hijacking of caspase-4/11 by ADP-riboxanation is more advantageous to bacterial virulence.

OspC3 blocked LPS-induced caspase-4 autoprocessing (Fig. 4f). This was recapitulated by mutations of Arg314 that also inhibited infection or LPS-induced pyroptosis (Fig. 4f, Extended Data Fig. 7a, b). Mutations of Arg310 in caspase-11 had the same effect (Extended Data Fig. 7c-e). OspC3 could also ADP-riboxanate already activated caspase-4/11 (Fig. 2b); the modified caspase-4/11-p20/p10, like their Arg314/Arg310 mutants, failed to target GSDMD (Fig. 4g, h, Extended Data Fig. 7f, g) owing to structural interference with the GSDMD-binding exosite $^{21}$. Arg314/Arg310, which are conserved in caspases (Extended Data Fig. 7h), coordinate substrate P1 aspartate; caspase-4/11-p20/p10 R314/R310 mutants could not cleave the peptide substrate (Extended Data Fig. 7i). Thus, ADP-riboxanation blocked caspase-4/11 activation and cleavage of their substrate.

We used the inactive OspC3E192A/H328A mutant (EH/AA) (Extended Data Fig. 6d-g) and assessed the function of caspase-11ADP-riboxanation in Shigella infection. WT mice survived S. flexneri $\Delta o s p C 3$ infection, and this effect was reversed by complementation with OspC3 WT but not the EH/AA mutant (Fig. 5a). Accordingly, mice infected with $\triangle o s p C 3$ alone or $\Delta$ ospC3 expressing OspC3 EH/AA had lower bacterial burdens than mice infected with WT OspC3-expressing strain (Fig. 5b). Unlike WT mice, Casp11 ${ }^{-/-}$mice succumbed equally to S. flexneri WT and e, Extracted ion chromatograms of the Arg314-containing peptide.f, Indicated SiHa or A431 cells expressing OspC3 or caspase-4 (WT or R314A) were electroporated with LPS or muramyl dipeptide (MDP). $\mathbf{g}, \mathbf{h}$, GSDMD was subjected to cleavage by an indicated form of caspase-4/11-p20/p10. Control (b, d), OspC3-modified caspase-4-p30-C/A. Data are representative of two (e,f) or three (b-d, $\mathbf{g}, \mathbf{h})$ independent experiments. For gel source data, see Supplementary Fig. 1.

$\Delta o s p C 3$, which replicated to a similarly high level. Notably, S. flexneri $\Delta o s p C 3$-infected mice produced much more anti-Shigella IgG than WT bacteria-infected mice at the $10 \% \mathrm{LD}_{50}$-normalized dose (the burden of $\Delta o s p C 3$ was not higher than WT bacteria at 24 h after infection), but this effect was abolished in $\mathrm{Casp}_{11^{-1-}}$ and $\mathrm{Gsdmd^{-1- }}$ mice (Fig. 5c, Extended Data Fig. 8a). $\Delta o s p C 3$-infected mice were more resistant to lethal S. flexneri re-infection, and this increased resistance was also absent

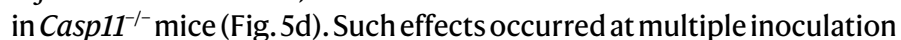
doses (Extended Data Fig. 8b, c). These findings suggest that caspase11-mediated pyroptosis has an intrinsic function of activating humoral immunity and also highlight the importance of OspC3-catalysed ADPriboxanation for evasion of caspase-11-mediated pyroptosis by Shigella.

Development of a Shigella vaccine has been challenging. $\Delta i c s A$ and $\triangle g u a B A$ mutants are being developed as live-attenuated vaccines ${ }^{22}$. Compared to $\triangle i c s A$ and $\triangle g u a B A, S$. flexneri $\triangle o s p C 3$ induced a higher level of anti-Shigella IgG (Extended Data Fig. 8d). Deletion of ospC3 on either $\triangle i c s A$ or $\triangle g u a B A$ background further boosted antibody production and conferred better protection from WT S. flexneri re-challenge (Fig. 5e, f). The better immunization of $\Delta i c s A \Delta o s p C 3$ over $\triangle i c s A$ also occurred at lower or higher inoculation doses in both $\mathrm{C} 57 \mathrm{BL} / 6$ and BALB/c mice (Extended Data Fig. 8e-h). These findings are valuable for Shigella vaccine development, although with the limitation of the mouse model.

A BLAST search identified 27 OspC homologues in diverse bacteria, including Vibrio, Salmonella, Erwinia and Chromobacterium (Extended Data Fig. 9a). Homology of their catalytic domains and ARDs to those of OspC3 ranges from $99 \%$ to $56 \%$ and from $100 \%$ to $27 \%$, respectively. Certain homologues readily ADP-riboxanated caspase-4/11 and blocked LPS-induced pyroptosis, and this effect was abolished by the corresponding EH/AA mutations (Extended Data Fig. 9b, c). For homologues 

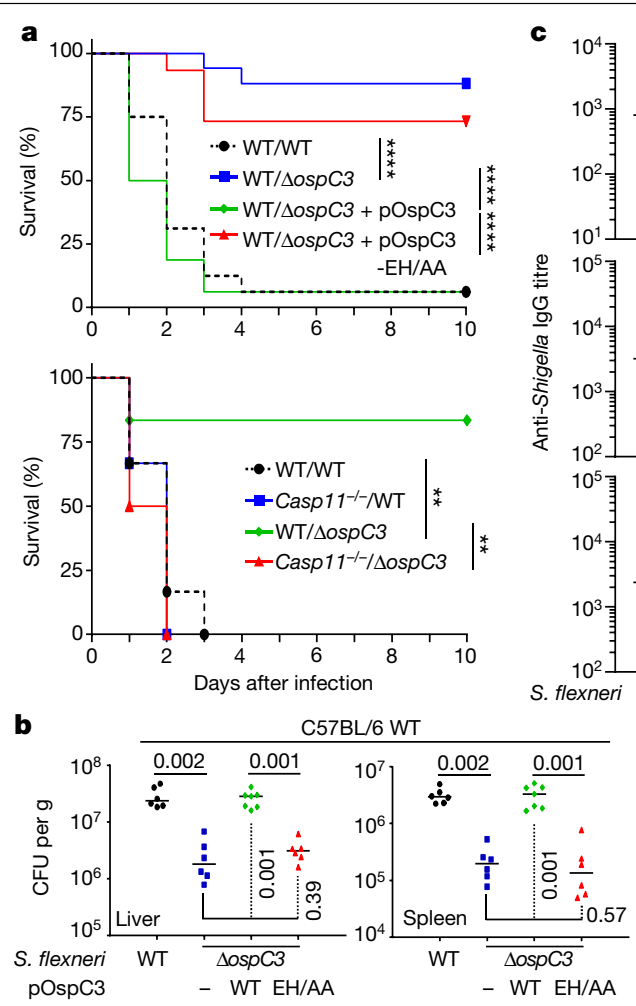
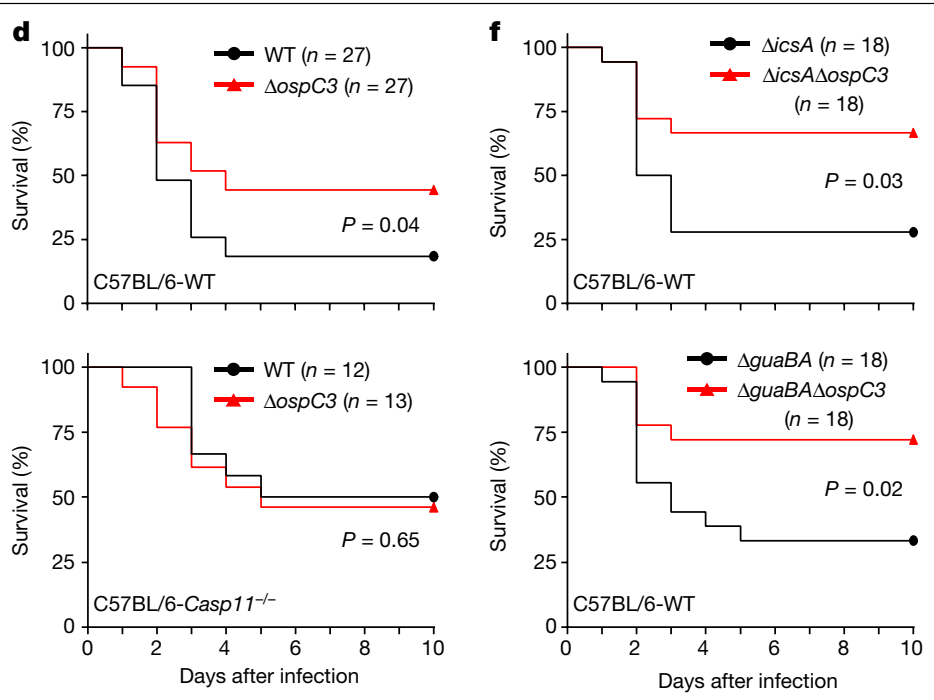
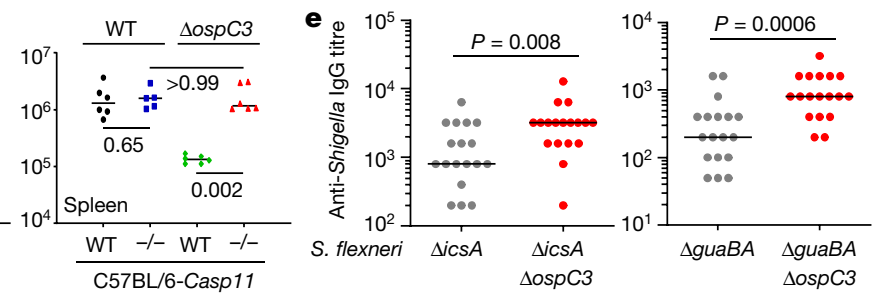

Fig. 5 | OspC3 underlies evasion by Shigella of pyroptosis-mediated defence that promotes anti-Shigella humoral immunity. a,b, WT and Casp11 $1^{-1-}$ mice were infected intraperitoneally with S. flexneri WT or an ospC3 deletion/ complementation strain $\left(2 \times 10^{7} \mathrm{CFU}\right.$ per mouse). a, Survival curves. Top, $n=16$ for WT/WT and WT/ $\Delta o s p C 3+$ pOspC $3, n=17$ for WT/ $/$ osp $C 3$ and $n=15$ for WT/ $\triangle o s p C 3+$ pOspC3-EH/AA. Bottom, $n=6$ for all groups. b, Bacterial loads. $n=5$ for $S$. flexneri WT-infected Casp $11^{-1-}$ mice, $n=7$ for $S$. flexneri $\Delta o s p C 3+$ pOspC3-infected WT mice and $n=6$ for all other groups. c-f, Indicated mice were immunized with S. flexneri WT or $\Delta o s p C 3\left(1.2 \times 10^{6}\right.$

that could not modify caspase-4/11, replacing their ARDs with that of OspC3 enabled the modification (Extended Data Fig. 9c). CopC from Chromobacterium violaceum, a deadly bacterium that causes hepatic abscesses in humans, could ADP-riboxanate caspase- 4 and inhibit LPS-induced pyroptosis, less potently than OspC3 (Extended Data Fig. $10 \mathrm{a}-\mathrm{c}$ ). CopC could also modify caspase-4/11 during infections, and C. violaceum $\triangle$ copC showed decreased replication in infected mouse liver (Extended Data Fig. 10d-f). Thus, OspC-like ADP-riboxanases are widely used by bacteria for various functions, including blocking pyroptosis.

In summary, Shigella uses OspC3 to modify caspase-11/4 and thereby thwart the inflammasome/pyroptosis-mediated defence. This differs from known bacterial inflammasome-modulating strategies that are self-alterations or indirect, such as inhibition of the Pyrin inflammasome by Yersinia YopM $^{23}$. Future studies will uncover other inflammasome/pyroptosis-targeting effectors. OspC3 catalyses arginine ADP-riboxanation; the activity is shared by the OspC family in bacteria. Arginine ADP-riboxanation might also exist in eukaryotes, and could be identified by mining ADP-ribosylome proteomic data.

\section{Online content}

Any methods, additional references, Nature Research reporting summaries, source data, extended data, supplementary information, acknowledgements, peer review information; details of author contributions and competing interests; and statements of data and code availability are available at https://doi.org/10.1038/s41586-021-04020-1.

and $4 \times 10^{6} \mathrm{CFU}$ per mouse in WT mice, respectively (both $10 \% \mathrm{LD}_{50}$ ); both $2 \times 10^{6}$ CFU per mouse in $\mathrm{Casp}_{11^{-1}}$ and $\mathrm{Gs} d \mathrm{md}^{-1-}$ mice) (c, d) or other deletion strains $\left(2 \times 10^{6} \mathrm{CFU}\right.$ per mouse) $(\mathbf{e}, \mathbf{f}) . \mathbf{c}, \mathbf{e}$, Anti-Shigella antibody in the sera of immunized mice. d, f, Indicated immunized mice were re-challenged with WT S. flexneri $\left(1.5 \times 10^{8} \mathrm{CFU}\right.$ per mouse in $\mathbf{d}$ and the upper panel of $f$ and $1 \times 10^{8} \mathrm{CFU}$ per mouse in the lower panel of f). a, d, f, Two-tailed log-rank (Mantel-Cox) test $\left({ }^{* * * *} P \leq 0.0001,{ }^{* * *} P \leq 0.001,{ }^{* *} P \leq 0.01\right) . \mathbf{b}, \mathbf{c}, \mathbf{e}$, Median values, two-tailed Mann-Whitney $U$-test. All data are representative of two independent experiments.
1. Shi, J. et al. Inflammatory caspases are innate immune receptors for intracellular LPS. Nature 514, 187-192 (2014).

2. Shi, J. et al. Cleavage of GSDMD by inflammatory caspases determines pyroptotic cell death. Nature 526, 660-665 (2015).

3. Kayagaki, N. et al. Caspase-11 cleaves gasdermin D for non-canonical inflammasome signalling. Nature 526, 666-671 (2015).

4. Ding, J. et al. Pore-forming activity and structural autoinhibition of the gasdermin family Nature 535, 111-116 (2016).

5. Broz, P., Pelegrin, P. \& Shao, F. The gasdermins, a protein family executing cell death and inflammation. Nat. Rev. Immunol. 20, 143-157 (2020).

6. Kayagaki, N. et al. Non-canonical inflammasome activation targets caspase-11. Nature 479, 117-121 (2011)

7. Rathinam, V. A. K., Zhao, Y. \& Shao, F. Innate immunity to intracellular LPS. Nat. Immunol. 20, 527-533 (2019).

8. Aachoui, Y. et al. Caspase-11 protects against bacteria that escape the vacuole. Science 339, 975-978 (2013).

9. Pilla, D. M. et al. Guanylate binding proteins promote caspase-11-dependent pyroptosis in response to cytoplasmic LPS. Proc. Natl Acad. Sci. USA 111, 6046-6051 (2014).

10. Tretina, K., Park, E. S., Maminska, A. \& MacMicking, J. D. Interferon-induced guanylate-binding proteins: guardians of host defense in health and disease. J. Exp. Med. 216, 482-500 (2019).

11. Li, P. et al. Ubiquitination and degradation of GBPs by a Shigella effector to suppress host defence. Nature 551, 378-383 (2017).

12. Wandel, M. P. et al. GBPs inhibit motility of Shigella flexneri but are targeted for degradation by the bacterial ubiquitin ligase IpaH9.8. Cell Host Microbe 22, 507-518 (2017).

13. Ji, C. et al. Structural mechanism for guanylate-binding proteins (GBPs) targeting by the Shigella E3 ligase IpaH9.8. PLoS Pathog. 15, e1007876 (2019).

14. Wandel, M. P. et al. Guanylate-binding proteins convert cytosolic bacteria into caspase-4 signaling platforms. Nat. Immunol. 21, 880-891 (2020).

15. Kobayashi, T. et al. The Shigella OspC3 effector inhibits caspase-4, antagonizes inflammatory cell death, and promotes epithelial infection. Cell Host Microbe 13 570-583 (2013).

16. $\mathrm{Xu}$, Y. et al. A bacterial effector reveals the V-ATPase-ATG16L1 axis that initiates xenophagy. Cell 178, 552-566 (2019).

17. Palazzo, L. et al. Processing of protein ADP-ribosylation by Nudix hydrolases. Biochem. J. 468, 293-301 (2015). 
18. Sauve, A. A. \& Schramm, V. L. SIR2: The biochemical mechanism of NAD+-dependent protein deacetylation and ADP-ribosyl enzyme intermediates. Curr. Med. Chem. 11, 807-826 (2004).

19. Handlon, A. L., Xu, C., Muller-Steffner, H. M., Schuber, F. \& Oppenheimer, N. J. 2'-Ribose substituent effects on the chemical and enzymic hydrolysis of NAD ${ }^{+}$. JACS 116, 12087-12088 (1994).

20. Bette-Bobillo, P., Giro, P., Sainte-Marie, J. \& Vidal, M. Exoenzyme S from P. aeruginosa ADP ribosylates rab4 and inhibits transferrin recycling in SLO-permeabilized reticulocytes. Biochem. Biophys. Res. Commun. 244, 336-341 (1998).

21. Wang, K. et al. Structural mechanism for GSDMD targeting by autoprocessed caspases in pyroptosis. Cell 180, 941-955 (2020).
22. Mani, S., Wierzba, T. \& Walker, R. I. Status of vaccine research and development for Shigella. Vaccine 34, 2887-2894 (2016).

23. Chung, L. K. et al. The Yersinia virulence factor YopM hijacks host kinases to inhibit type III effector-triggered activation of the pyrin inflammasome. Cell Host Microbe 20, 296-306 (2016).

Publisher's note Springer Nature remains neutral with regard to jurisdictional claims in published maps and institutional affiliations.

(c) The Author(s), under exclusive licence to Springer Nature Limited 2021 


\section{Methods}

No statistical methods were used to predetermine sample size. The experiments were not randomized, and investigators were not blinded to allocation during experiments and outcome assessment.

\section{Plasmids, antibodies and reagents}

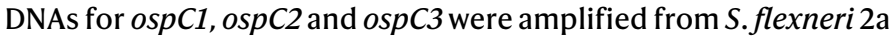
strain 2457T. DNA for exoS was amplified from Pseudomonas aeruginosa strain PAO1. DNA for sdeA was amplified from Legionella pneumophila strain Lp02. DNA for $\operatorname{copC}$ was amplified from the genomic DNA of $C$. violaceum strain 12472. Complementary DNA (cDNA) for NUDT16 was from an ORF library of Invitrogen (clone ID: IOH61424). cDNAs for human caspase-4, GSDMD, Rab4A, YWHAB and caspase-11 were described previously ${ }^{2,24,25}$. The DNAs were ligated into pCS2-Flag, pCS2-3×Flag, pCS2-3×Flag-GST, pCS2-3×HA, pLVX-3×Flag or FUIGW-Flag vectors for transient or stable expression in mammalian cells. For recombinant protein expression in E. coli, the DNAs were inserted into pGEX-6p-2, pET28a-6×His, pET28a-6×His-SUMO, pET21a, pACYCDuet-1, pQE-30 or pAC-SUMO (generated by replacing the replication origin of $\mathrm{pET} 28 \mathrm{a}-6 \times \mathrm{His}-\mathrm{SUMO}$ with the $\mathrm{p} 15 \mathrm{~A}$ replicon derived from the $\mathrm{pACYC}$ vector). For complementation in the S. flexneri $\Delta o s p C 3$ strain, C-terminal Flag-tagged DNAs for ospC3 and its mutants, together with its native promoter sequence, were cloned into the pET28a vector. The pSpCas9(BB)-2A-GFP plasmid (PX458) used for generating knockout cells was obtained from Addgene (48138). All truncations and point mutations were generated by the standard polymerase chain reaction (PCR) cloning method. All plasmids were verified by DNA sequencing.

Monoclonal antibodies against human GSDMD (ab210070/ EPR19829), mouse GSDMD (ab219800/EPR20859), human cleaved GSDMD-C domain (ab227821/EPR20885-203) ${ }^{21}$ and mouse cleaved GSDMD-C domain (ab255603/EPR20859-147) ${ }^{21}$ were from Abcam. Antibodies against Flag (F3165/M2 and F7425/polyclonal) and tubulin (T5168/B-5-1-2) were from Sigma-Aldrich. The anti-HA antibody (3724/ C29F4) was from Cell Signaling Technology, and rabbit Fc-fused monoADP-ribose binding reagent (MABE1076) was from Sigma-Aldrich. The monoclonal antibody for caspase- 4 and polyclonal antibody for caspase-11 were generated by the in-house facility at the National Institute of Biological Sciences (NIBS) in Beijing, China. For western blot, horseradish peroxidase (HRP)-conjugated anti-mouse IgG (NA931/ polyclonal) and HRP-conjugated anti-rabbit IgG (NA934/polyclonal) were purchased from GE Healthcare Life Sciences. For enzyme-linked immunosorbent assay (ELISA), HRP-conjugated goat anti-mouse IgG (1036-05/polyclonal) was purchased from SouthernBiotech (lot no. D4913-WJ86H). Antibodies for Flag and tubulin were used at 1:5,000 dilution, and all other primary antibodies were used at 1:1,000 dilution for western blot. Secondary antibodies were used at 1:5,000 and 1:6,000 dilutions for western blot and ELISA, respectively.

The following chemical reagents were purchased from Sigma-Aldrich: $\mathrm{NAD}^{+}(\mathrm{N} 1636), \mathrm{NADH}(\mathrm{N} 8129), \mathrm{NADPH}(\mathrm{N} 7505), \mathrm{NGD}^{+}(\mathrm{N} 5131), \varepsilon-\mathrm{NAD}^{+}$ (N2630), Thio-NAD ${ }^{+}\left(\mathrm{T}_{7375}\right)$, Deamino-NAD ${ }^{+}(\mathrm{N} 6506), \mathrm{NAAD}^{+}(\mathrm{N} 4256)$, $\alpha-\mathrm{NAD}^{+}(\mathrm{N} 6754), \alpha-\mathrm{NADH}(\mathrm{N} 6879), \mathrm{NMN}^{+}(\mathrm{N} 3501), \mathrm{ADPR}(\mathrm{A0752})$ and ninhydrin (N4876). The ammonia assay kit (MAK310) was also from Sigma-Aldrich. 2'-F-NAD ${ }^{+}$(D148) was from the BIOLOG Life Science Institute. Biotin-NAD ${ }^{+}$(4670-500-01) was from Trevigen. Thio-NADH (BIB5005) was from Apollo Scientific. $\mathrm{NADP}^{+}$(432216) was from J\&K Scientific. Cyclic-ADPR (21417) was from Cayman Chemical. $2^{\prime}-\mathrm{H}^{-N A D^{+}}$ was synthesized at the chemical centre of our institute. All other chemical reagents used were from Sigma-Aldrich unless otherwise noted.

\section{Bacterial strains and infection}

S. flexneri 2a strain 2457T, B. thailandensis $\mathrm{E} 264$, C. violaceum 12472 and $S$. Typhimurium SL1344 were used in cell culture infections, and the first three were used to infect mice. S. flexneri $\Delta o s p C 1, \Delta o s p C 2$ and $\Delta o s p C 3$ mutants were generated by using the $\lambda$ Red recombineering method ${ }^{26}$. C. violaceum $\triangle$ copC was generated by homologous recombination using the suicide vector pDM4-SacB.S. flexneri $\Delta i p a H 9.8$ and $S$. Typhimurium $\Delta$ sifA have been described previously ${ }^{1,11}$. For infection in epithelial cells, S. flexneri strains were transformed with an afimbrial adhesin (Afa) locus to achieve high infection efficiency. For in vivo infection, the mouse-passaged $B$. thailandensis strain was used ${ }^{8}$.

Cultured cells were seeded in 24-well plates 12-16 h before infection. iBMDMs were primed with $0.1 \mu \mathrm{g} \mathrm{ml}^{-1}$ of LPS for $16 \mathrm{~h}$ to stimulate caspase-11 expression. The bacteria were cultured overnight at $37^{\circ} \mathrm{C}$ in $2 \times$ YT medium with shaking at $220 \mathrm{rpm}$. Overnight bacterial cultures were diluted 1:50 (1:20 for $B$. thailandensis) in fresh $2 \times$ YT medium and cultured at $37^{\circ} \mathrm{C}$ with shaking for about $3.5 \mathrm{~h}(4.5 \mathrm{~h}$ for $B$. thailandensis) when $\mathrm{OD}_{600}$ reached about 1.7. Bacteria were diluted in serum-free Dulbecco's modified Eagle's medium (DMEM) to achieve the desired multiplicity of infection (MOI: 25 for S. flexneri; 50 for $S$. Typhimurium; 100 for B. thailandensis; and 10 for $C$. violaceum). Infection was started by centrifugation at $800 \mathrm{~g}$ for $5 \mathrm{~min}$ at room temperature followed by incubation at $37^{\circ} \mathrm{C}$ in a $5 \% \mathrm{CO}_{2}$ incubator. After $1 \mathrm{~h}$ of infection $(0.5 \mathrm{~h}$ for $S$. Typhimurium in iBMDMs, $1.5 \mathrm{~h}$ for $B$. thailandensis), cell culture media were replaced with fresh serum-free DMEM supplemented with appropriate antibiotics $\left(100 \mu \mathrm{g} \mathrm{ml}^{-1}\right.$ of gentamycin and $34 \mu \mathrm{g} \mathrm{ml}^{-1}$ of chloramphenicol for $S$. flexneri and $S$. Typhimurium, $100 \mu \mathrm{g} \mathrm{ml}^{-1}$ of gentamycin for $B$. thailandensis). Infected cells were further incubated for different time durations dependent upon the context of infection. Specifically, iBMDMs were incubated for $1 \mathrm{~h}$ ( $S$. Typhimurium), $2.5 \mathrm{~h}$ (S. flexneri) and $6.5 \mathrm{~h}$ (B. thailandensis); $\mathrm{SiHa}$ and A431 cells were incubated for $3.5 \mathrm{~h}$. The cell culture media were collected and subjected to LDH release assay or trichloroacetic acid precipitation to obtain released protein samples. Infection of A431 cells with S. flexneri was performed in the presence of $4 \mu \mathrm{M}$ human $\alpha$-defensin 5 (kindly provided by Dr. Dan Xu, Xi'an Jiaotong University, China). The LDH assay was performed using the CytoTox 96 Non-Radioactive Cytotoxicity Assay Kit (Promega).

WT C57BL/6 mice, purchased from Beijing Vital River Laboratory Animal Technology, and Casp $11^{-1-} \mathrm{C} 57 \mathrm{BL} / 6$ mice $^{6}$, were used for infection in animals. All mice were maintained in the specific pathogen-free facility at NIBS under standard housing conditions (12-h dark/light cycle, $20-26^{\circ} \mathrm{C}, 40-70 \%$ humidity, noise $\leq 60 \mathrm{~dB}$ ) in accordance with the national guidelines for housing and care of laboratory animals (National Health Commission, China). Mice were transferred to a Biosafety Level 2 facility with the same housing conditions to conduct infections. The protocols for mouse experiments are in accordance with institutional regulations after review and approval by the Institutional Animal Care and Use Committee of NIBS. The bacteria were cultured overnight at $37^{\circ} \mathrm{C}$ in $2 \times$ YT medium with shaking at $220 \mathrm{rpm}$. Overnight cultures were diluted 1:100 in fresh $2 \times$ YT medium and grown until $\mathrm{OD}_{600}$ reached 1.5. The bacteria were collected by centrifugation $(4,000 \mathrm{rpm}$. for $5 \mathrm{~min})$ and re-suspended in PBS. Next, 8-10-week-old female mice were infected intraperitoneally with $200 \mu$ l of bacteria suspension $\left(2 \times 10^{7}\right.$ colony-forming units (CFU) for each mouse). For infection of C. violaceum, 7-week-old female mice were infected intravenously with $5 \times 10^{3}$ C. violaceum (in $200 \mu \mathrm{l}$ of PBS). Survival of mice was checked daily for $10 \mathrm{~d}$. To measure bacterial burden, livers and spleens of infected mice were collected $13-16 \mathrm{~h}$ after infection and homogenized in sterile PBS. The CFU numbers in the tissue were measured by plating serial-diluted homogenates on $2 \times$ YT agar plates.

\section{Mice immunisation and ELISA}

Female C57BL/ 6 and BALB/c mice ( 8 weeks old) were immunized by intraperitoneal injection of bacteria $\left(1.2 \times 10^{6} \mathrm{CFU}\right.$ for WT S. flexneri, $4 \times 10^{6} \mathrm{CFU}$ for $\Delta o s p C 3$ mutant and $2 \times 10^{6} \mathrm{CFU}$ for all candidate vaccine strains unless specifically indicated) re-suspended in $200 \mu$ l of PBS. Owing to the more efficient clearance of the $\Delta o s p C 3$ strain in mice, the doses of immunization for WT and the $\Delta o s p C 3$ mutant were normalized 
by their virulence, and $10 \%$ of the median lethal dose $\left(\mathrm{LD}_{50}\right)$ of each strain was used. Sera samples were collected $14 \mathrm{~d}$ after the immunisation, and Shigella-specific antibody levels were assessed by standard ELISA assay. In brief, 96-well ELISA plates (Nunc MaxiSorp) were coated with $2 \times 10^{7}$ CFU of live $S$. flexneri re-suspended in $100 \mu \mathrm{l}$ of carbonate-bicarbonate buffer ( $\mathrm{pH} 9.6$ ) at $4{ }^{\circ} \mathrm{C}$ overnight. The Shigella-coated plates were washed three times with PBST buffer (0.05\% Tween 20 in PBS) before blocking with $200 \mu \mathrm{l}$ of the buffer (2\% BSA in PBST) for $2 \mathrm{~h}$ at $37^{\circ} \mathrm{C}$. After washing with PBST three times, twofold serial dilutions of the sera (diluted in the blocking buffer) were added to the plates $(100 \mu \mathrm{l}$ per well) and incubated for $2 \mathrm{~h}$ at $37^{\circ} \mathrm{C}$. The plates were then washed four times with PBST before adding HRP-conjugated goat anti-mouse IgG antibody (1:6,000 diluted in the blocking buffer, $100 \mu$ l per well) for $1 \mathrm{~h}$ at $37^{\circ} \mathrm{C}$. After washing with PBST four times, peroxidase substrate $o$-phenylenediamine $\left(0.4 \mathrm{mg} \mathrm{ml}^{-1}\right.$, dissolved in $0.15 \mathrm{M}$ phosphate-citrate buffer supplemented with $0.03 \% \mathrm{H}_{2} \mathrm{O}_{2}, \mathrm{pH}$.0) was added to the plates $(100 \mu \mathrm{l}$ per well) and incubated for $15 \mathrm{~min}$ at room temperature. The reaction was then stopped by adding $2 \mathrm{M} \mathrm{H}_{2} \mathrm{SO}_{4}(50 \mu \mathrm{l}$ per well), and $\mathrm{OD}_{492}$ was measured. Antibody titres were defined as the reciprocal of the last dilution having an $\mathrm{OD}_{492}$ value at least twofold higher than that obtained in the control wells; the blocking buffer was used as the mock serum sample.

\section{Cell culture, transfection and immunoprecipitation}

HeLa, SiHa, A431, 293T and iBMDM cells were grown in DMEM supplemented with $10 \%(\mathrm{v} / \mathrm{v})$ FBS and $2 \mathrm{mM}$ L-glutamine. All cell lines were obtained from the American Type Culture Collection except for the previously described iBMDMs ${ }^{1}$. Cells were maintained at $37^{\circ} \mathrm{C}$ in a humidified $5 \% \mathrm{CO}_{2}$ incubator. All cells were tested for mycoplasma using the standard PCR method. Cell identity was checked frequently by morphological features but was not authenticated by short tandem repeat profiling. Knockout cell lines were generated by the CRISPRCas 9 method as previously described ${ }^{1}$. In brief, PX458 plasmids containing the guide RNAs targeting Casp1, Casp11 or CASP4 were electroporated into the cells ( $1 \mu \mathrm{g}$ of DNA per $1 \times 10^{6}$ cells). Three days later, GFP-positive cells were sorted into single clones on 96-well plates by flow cytometry. Single clones were screened and verified by sequencing of the PCR fragments and confirmed by western blot. Sequences for the guide RNAs used are 5'-GGAATTCTGGAGCTTCAATC-3' for CASP1, 5'-GGTCCACACTGAAGAATGTC-3' for Casp11 and 5'-CAAGAGAAGCAACGTATGGC-3' for CASP4. The HeLa CASP4 ${ }^{-/-}$cell line was described previously ${ }^{1}$. Transient transfection was performed using jetPRIME (Polyplus-transfection) following the manufacturer's instructions. Cell lines with stable gene expression were generated by lentiviral infection as previously described ${ }^{1}$. For immunoprecipitation, $293 \mathrm{~T}$ cells grown to $60 \%$ confluence were transfected with indicated plasmids. Twenty-four hours after transfection, cell pellets were harvested and lysed in the lysis buffer (50 mM Tris- $\mathrm{HCl}, \mathrm{pH} 7.6,150 \mathrm{mM}$ $\mathrm{NaCl}, 1 \mathrm{mM} \mathrm{CaCl}_{2}, 1 \%$ Triton X-100 and a protease inhibitor cocktail) for $0.5 \mathrm{~h}$ followed by centrifugation at $4{ }^{\circ} \mathrm{C}(15,000 \mathrm{rpm}$ for $10 \mathrm{~min})$. The lysates were incubated with anti-Flag M2 affinity beads at $4{ }^{\circ} \mathrm{C}$ with gentle rotation for $2 \mathrm{~h}$. The beads were washed five times with the lysis buffer, and the immunoprecipitants were eluted from the beads with Flag or $3 \times$ Flag peptides.

\section{Recombinant protein purification}

The $E$. coli $\mathrm{BL} 21$ (DE3) strain was used for all recombinant protein expression. Induction of protein expression $\left(18^{\circ} \mathrm{C}\right.$ for $16 \mathrm{~h}$ ) was achieved with $0.4 \mathrm{mM}$ isopropyl $\beta$-D-1-thiogalactopyranoside after $\mathrm{OD}_{600}$ of bacterial culture reached 1.0. Bacterial cells were harvested and lysed by an ultrasonic homogenizer in buffer containing 20 mM HEPES ( $\mathrm{pH} 7.0$ ), $300 \mathrm{mM} \mathrm{NaCl}, 5 \mathrm{mM} \mathrm{CaCl}_{2}$ and $5 \mathrm{mM}$ dithiothreitol. GST-fusion OspC or OspC chimeric proteins were purified by glutathione sepharose affinity chromatography. The GST tag was removed by overnight digestion with homemade PreScission Protease (PPase) at $4{ }^{\circ} \mathrm{C}$. The untagged proteins were further purified by HiTrap SP HP cation exchange chromatography and Superdex G75 gel filtration chromatography (GE Healthcare Life Sciences). The purified proteins were concentrated and stored at $-80^{\circ} \mathrm{C}$ in buffer containing $20 \mathrm{mMHEPES}$ (pH 7.0), $150 \mathrm{mM} \mathrm{NaCl}, 2 \mathrm{mM}$ $\mathrm{CaCl}_{2}$ and $5 \mathrm{mM}$ dithiothreitol. pAC-SUMO-CASP4-p30-C/A plasmid was used to express caspase-4-p30-C/A protein. Bacteria cells were harvested and lysed in the buffer containing $20 \mathrm{mM} \mathrm{Tris-} \mathrm{HCl}(\mathrm{pH} 8.0)$, $300 \mathrm{mM} \mathrm{NaCl}, 20 \mathrm{mM}$ imidazole and $10 \mathrm{mM}$ 2-mercaptoethanol. The $\mathrm{His}_{6}$-SUMO-tagged protein was first purified by affinity chromatography using $\mathrm{Ni}$-chelating sepharose resin, and the tag was removed by overnight digestion at $4{ }^{\circ} \mathrm{C}$ with homemade ULP1 protease. The untagged protein was further purified by HiTrap Q HP anion exchange and Superdex G75 gel filtration chromatography. Purified caspase-4 proteins were concentrated and stored at $-80^{\circ} \mathrm{C}$ in buffer containing $20 \mathrm{mM}$ Tris- $\mathrm{HCl}$ (pH 8.0), $150 \mathrm{mM} \mathrm{NaCl}$ and $5 \mathrm{mM}$ dithiothreitol. A similar procedure was followed to purify other $\mathrm{His}_{6}$-SUMO-tagged proteins, including caspase-11-p30-C/A, GSDMD, NUDT16, ExoS (ADP-ribosyltransferase domain starting from Ala233), Rab4a, 14-3-3 $\beta$, ADPRH, ADPRS, OARD1, MACROD2 and $\mathrm{His}_{6}$-tagged MACROD1 (starting from Thr91). Accession numbers (for the NCBI protein database, https://www.ncbi. nlm.nih.gov/protein/) of the proteins used in this study are: OspC3 (WP_015683184.1),OspC2(WP_000701108.1), OspC1(WP_001026857.1), CASP4 (NP_001216.1), CASP11(NP_031635.2), GSDMD(NP_001159709.1), NUDT16 (NP_689608.2), ExoS(WP_003113791.1), RAB4A(NP_004569.2), 14-3-3 (NP_647539.1), ADPRH (NP_001116.1), ADPRS (NP_060295.1), OARD1 (NP_001316613.1), MACROD2 (NP_542407.2) and MACROD1 (NP_054786.2).

\section{OspC3-catalysed modification reaction and native-PAGE}

The reaction was carried out in a buffer containing $20 \mathrm{mM}$ HEPES (pH 7.0), $150 \mathrm{mM} \mathrm{NaCl}, 1 \mathrm{mM} \mathrm{CaCl}_{2}$ and $5 \mathrm{mM}$ dithiothreitol. Purified caspase-4/11-p30-C/A and OspC3 proteins (molar ratio:1:1) were incubated at $16^{\circ} \mathrm{C}$ for $12 \mathrm{~h}$ in the presence of $1 \mathrm{mM} \mathrm{NAD}$. Native-PAGE was used to analyse OspC3-catalysed modification of caspase-4/11. Samples of the in vitro reaction or the purified protein were separated on a 4-20\% gradient non-denaturing polyacrylamide gel in a buffer containing $25 \mathrm{mM}$ Tris ( $\mathrm{pH} \mathrm{8.3)} \mathrm{and} 192 \mathrm{mM}$ glycine. The electrophoresis was started at a voltage of $90 \mathrm{~V}$; the voltage was gradually increased to $180 \mathrm{~V}$, and the electrophoresis was stopped until the dyes in the loading buffer (bromophenol blue and xylene cyanol FF) migrated out of the gel. The gel was stained with Coomassie Brilliant Blue R-250 to visualize the mobility shift of the modified caspase- $4 / 11$ protein.

\section{Stable isotope labelling by amino acids in cell culture experiment}

293T cells were first adapted to SILACDMEM medium in which L-arginine was replaced by heavy isotope labelled arginine (L-arginine $-{ }^{13} \mathrm{C}_{6},{ }^{15} \mathrm{~N}_{4}$ ), and regular FBS was replaced by dialysed FBS. The cells were cultured in SILAC DMEM medium and passaged at a ratio of 1:10 for five times to ensure complete incorporation, which was further checked by LC-MS analysis before the experiment. Flag-caspase-4 p20/p10 complexes were expressed alone or co-expressed with OspC3 by transient transfection in the adapted 293T cells. Thirty-six hours after transfection, cell pellets were harvested and lysed in a buffer containing $50 \mathrm{mM} \mathrm{Tris-HCl}$ (pH 7.6), $150 \mathrm{mM} \mathrm{NaCl}, 1 \%$ Triton X-100 and a protease inhibitor cocktail. Standard immunoprecipitation was performed to purify caspase- 4 p20/p10 proteins that were subjected to subsequent LC-MS analyses.

\section{MS}

For LC-MS/MS identification of the modified peptides, samples were separated on an SDS-PAGE gel, and the protein bands of interest were reduced and alkylated using dithiothreitol and iodoacetamide, respectively. The protein samples were digested overnight with chymotrypsin. The resulting peptides were dried on a SpeedVac vacuum concentrator and then re-suspended in an aqueous buffer before LC-MS/MS analysis. 


\section{Article}

A Hybrid Ion Trap Orbitrap mass spectrometer (LTQ Orbitrap Velos, Thermo Fisher Scientific) was used to identify and analyse the modified peptides, and profiling of the modification sites was performed on the Orbitrap Fusion Lumos mass spectrometer (Thermo Fisher Scientific).

For CID-MS and EThcD-MS analyses, a capillary column $(75 \mu \mathrm{m} \times 150 \mathrm{~mm})$ with a laser-pulled electrospray tip (Model P-2000, Sutter Instrument) was home-packed with 4-mm,100-Å Magic C18AQ silica-based particles. The LC mobile phase comprised solvent A ( $97 \%$ $\mathrm{H}_{2} \mathrm{O}, 3 \%$ acetonitrile and $0.1 \%$ formic acid) and solvent $\mathrm{B}(80 \%$ acetonitrile, $20 \% \mathrm{H}_{2} \mathrm{O}$ and $0.1 \%$ formic acid). An EASY-nLC $1200 \mathrm{HPLC}$ system (Thermo Fisher Scientific) was used to generate the following HPLC gradient: solvent B was increased from $7 \%$ to $40 \%$ in 40 min and then raised to $95 \%$ in $2 \mathrm{~min}$ and kept for $10 \mathrm{~min}$ followed by $100 \%$ solvent A for column equilibration. A data-dependent acquisition mode was enabled for peptide fragmentation with one full MS scan $(\mathrm{m} / \mathrm{z}$ range $350.00-1,200.00$, resolution 60,000 ) followed by CID. To identify the modification site, precursor ions were subjected to $E T h c D$ for peptide fragmentation. Raw MS files were processed using Mascot (version 2.3.02, Matrix Science). The following settings were used for database search: $20 \mathrm{ppm}$ precursor mass error tolerance and 0.8-Da fragment mass error tolerance for LTQ Orbitrap Velos and 10 p.p.m. precursor mass error tolerance and 0.02-Da fragment mass error tolerance for Orbitrap Fusion Lumos. Carbamidomethylation of cysteine residues was set as a fixed modification, and oxidation of methionine was set as a variable modification. A maximum of two missed cleavage sites was allowed. Peptide and protein identifications were filtered at less than $1 \%$ false discovery rates. The corresponding peptide peaks were obtained from Thermo Xcalibur 2.2 (Thermo Fisher Scientific).

To measure the total molecular weight of caspase- 4 or -11 , the purified proteins were separated on $\mathrm{C}_{18}$ reversed-phase column. The EASY-nLC $1200 \mathrm{HPLC}$ system was used to generate the following gradient: $20-50 \%$ $\mathrm{B}$ in $20 \mathrm{~min}, 50-70 \% \mathrm{~B}$ in $3 \mathrm{~min}$ and maintained at $70 \% \mathrm{~B}$ for $20 \mathrm{~min}$. MS data were processed using Thermo Scientific Protein Deconvolution software. The parameters were specified according to the mass spectrometer setting. Deconvoluted mass of the most abundant ion was selected as the mass of the target protein with a mass tolerance of $30 \mathrm{ppm}$.

\section{Reporting summary}

Further information on research design is available in the Nature Research Reporting Summary linked to this paper.

\section{Data availability}

All data supporting the findings of this study are included in this manuscript and its Supplementary Information. Source data are provided with this paper.

24. Dong, N. et al. Structurally distinct bacterial TBC-like GAPs link Arf GTPase to Rab1 inactivation to counteract host defenses. Cell 150, 1029-1041 (2012).

25. Gao, W., Yang, J., Liu, W., Wang, Y. \& Shao, F. Site-specific phosphorylation and microtubule dynamics control Pyrin inflammasome activation. Proc. Natl Acad. Sci. USA 113, E4857-E4866 (2016)

26. Murphy, K. C. \& Campellone, K. G. Lambda Red-mediated recombinogenic engineering of enterohemorrhagic and enteropathogenic E. coli. BMC Mol. Biol. 4, 11 (2003).

Acknowledgements We thank L. Li and S. Chen for mass spectrometry, P. Li and H. He for technical assistance and C. Li for advice. The work was supported by National Key Research and Development Programs of China (2017YFA0505900 and 2016YFA0501500), the Strategic Priority Research Program of the Chinese Academy of Sciences (XDB37030202 and XDB29020202), the National Natural Science Foundation of China $(81788104,81922043$, 21622501 and 21974002) and the Chinese Academy of Medical Sciences Innovation Fund for Medical Sciences (2019-12M-5-084).

Author contributions Z.L., W.L. and F.S. conceived the study. Z.L. performed most of the biochemical and functional experiments. W.L. made the initial observation of a possible new PTM on caspase-11 by OspC3. J.F. S.C. and X.L. were responsible for mass spectrometry and data analyses. Z.W. and X.Q. synthesized 2'-H-NAD+. Y.X., Y.L., X.L., X.S. and J.D. provided technical assistance and valuable suggestions. Z.L. and F.S. analysed the data and wrote the manuscript, with input from all authors. All authors discussed the results and commented on the manuscript.

Competing interests The authors declare no competing interests.

Additional information

Supplementary information The online version contains supplementary material available at https://doi.org/10.1038/s41586-021-04020-1.

Correspondence and requests for materials should be addressed to Xiaoyun Liu or Feng Shao.

Peer review information Nature thanks Klaus Aktories and the other, anonymous, reviewer(s) for their contribution to the peer review of this work.

Reprints and permissions information is available at http://www.nature.com/reprints. 

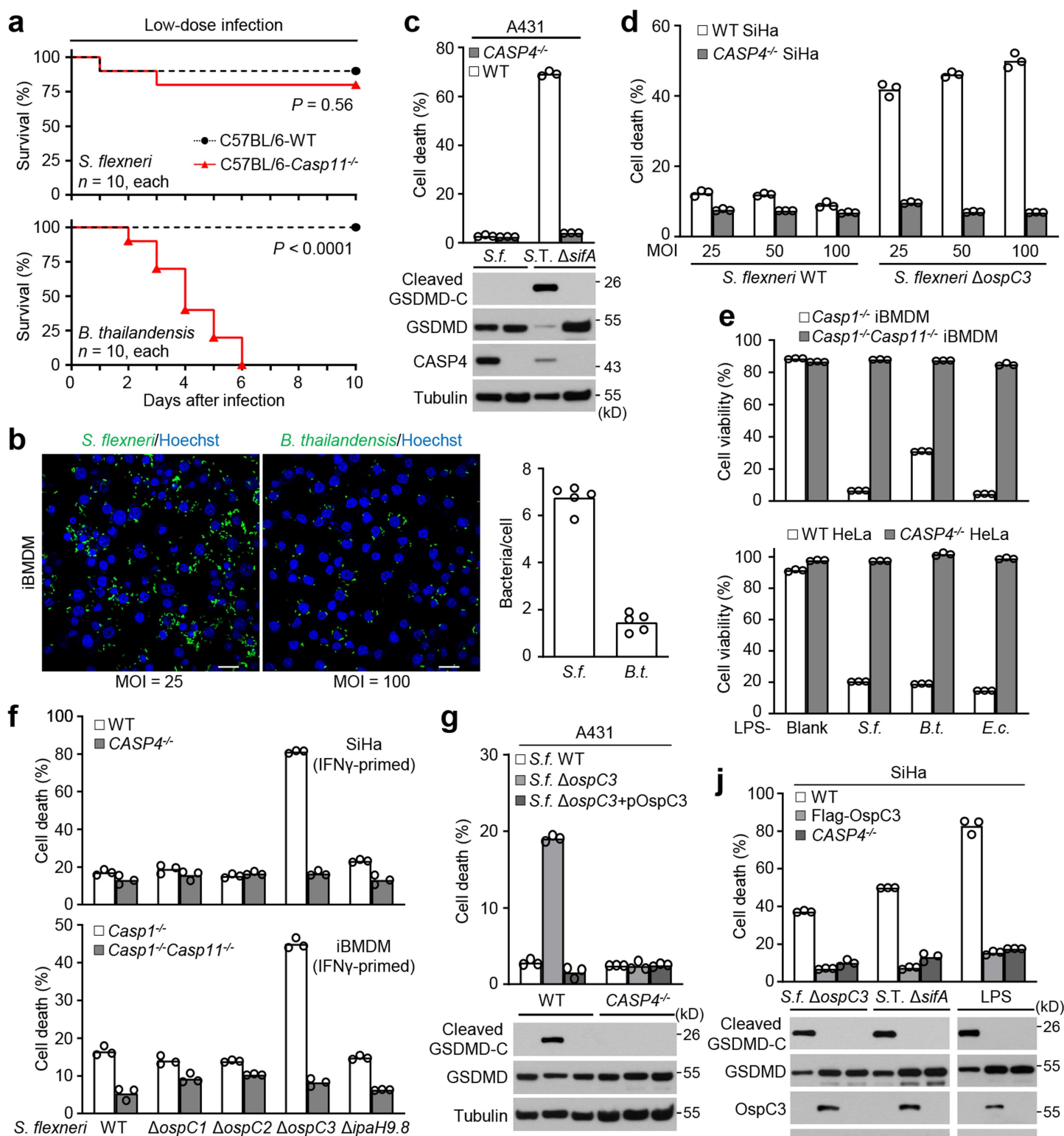

g
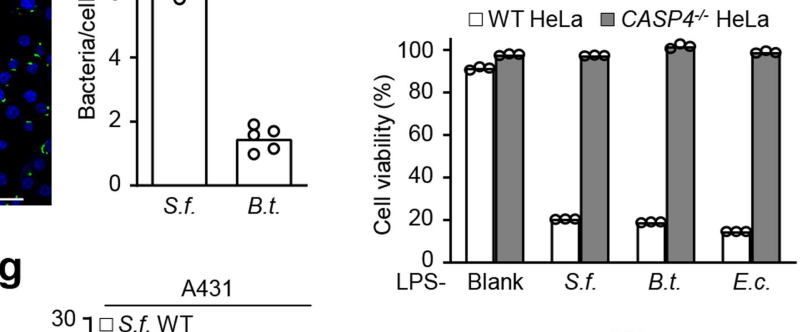

s. flexneri WT $\triangle o s p C 1 \triangle o s p C 2 \triangle o s p C 3 \triangle i p a H 9.8$
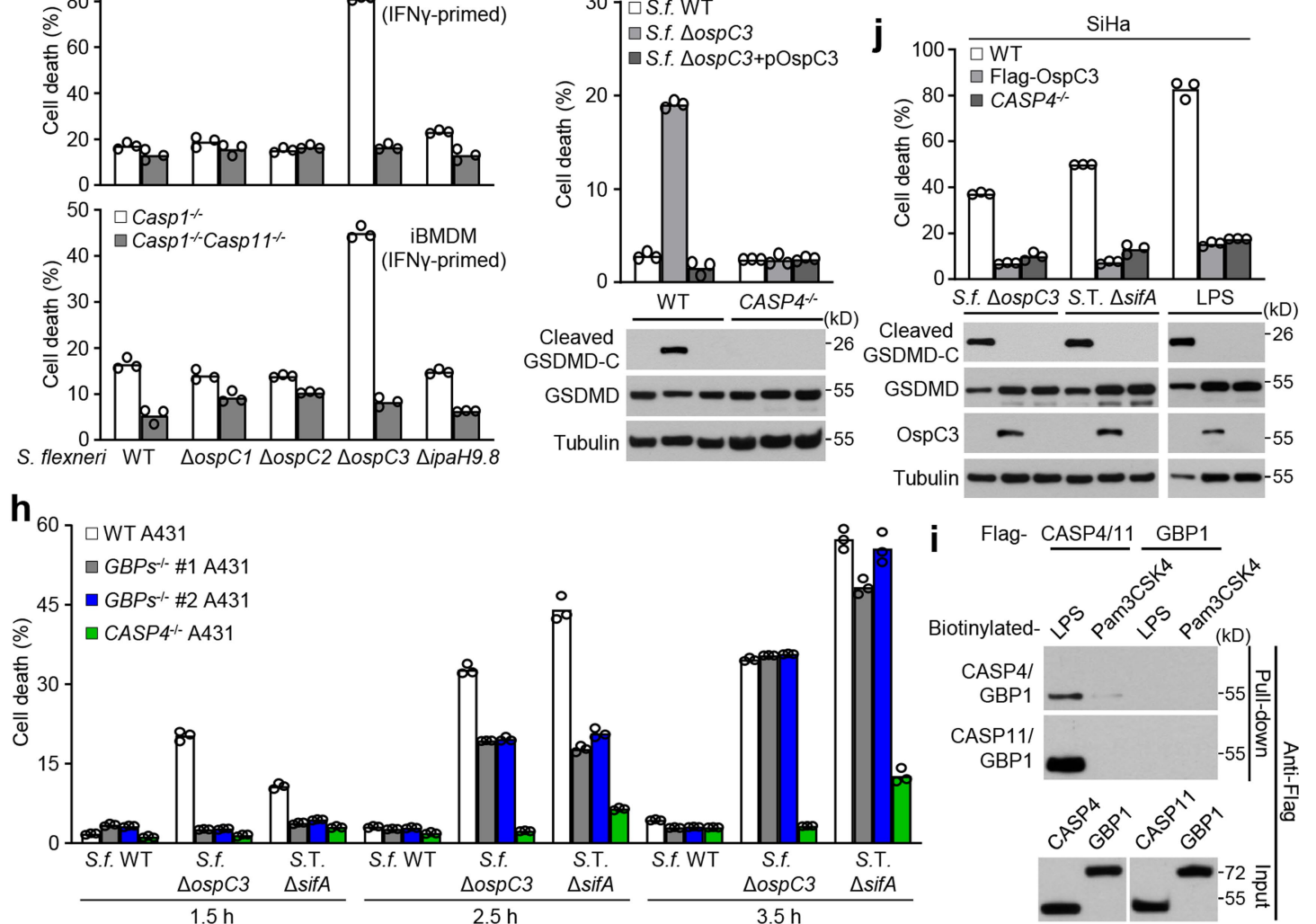

Extended Data Fig. 1 |See next page for caption. 


\section{Article}

Extended Data Fig. $1 \mid$ S. flexneri suppresses cytosolic LPS-induced host defense through the OspC3 effector. a, Survival curves of WT or Casp11 ${ }^{-1}$ mice infected intraperitoneally with $S$. flexneri or B. thailandensis $\left(5 \times 10^{6}\right.$ CFU per mouse, $n=10$ for each group; two-tailed log-rank (Mantel-Cox) test).

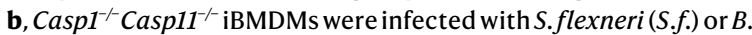
thailandensis (B.t.) at the indicated MOIs for $1.5 \mathrm{~h}$. Extracellular bacteria were killed by gentamycin. Intracellular bacteria were stained by anti-Shigella or anti-Burkholderia antibodies (scale bar, $20 \mu \mathrm{m}$ ). The numbers of bacteria/cell (mean values) were calculated from 5 randomly selected images.c, g, WT or $\mathrm{CASP}^{-/-} \mathrm{A} 431$ cells were infected with S. flexneri (WT, an ospC3 deletion or complementation (pOspC3) strain) or S. Typhimurium $\triangle$ sifA.d, WT or CASP4 $\mathrm{SiH}$ a cells were infected with $S$. flexneri WT or $\Delta o s p C 3$ at the indicated MOIs. e, Indicated cells were electroporated with LPS purified from S. flexneri, B. thailandensis or E. coli (E.c.).f, WT or CASP4 ${ }^{-1-}$ SiHa cells and $C a s p 1^{-1-}$ or

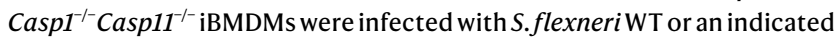

mutant. h, WT or $\mathrm{CASP} 4^{--}$or $\mathrm{GBPs}^{-/-}$(lacking all seven human GBPs) A431 cells were infected with indicated bacteria strains; cell death was assayed at the indicated time points post-infection. $\mathbf{i}$, Streptavidin pull-down assay of the binding of biotin-conjugated LPS or Pam3CSK4 to Flag-tagged caspase-4/11-C/A and GBP1 in transfected 293 T cell lysates.j, WT, CASP4 ${ }^{-/-}$, or OspC3-expressing SiHa cells were infected with S.flexneri $\Delta$ ospC3 or $S$. Typhimurium $\Delta$ sifA, or electroporated with LPS. c, g,j, Cell lysates were immunoblotted as shown and supernatants were blotted with the anti-cleaved GSDMD-C antibody. $\mathbf{f}, \mathbf{h}$, Cells were primed with $100 \mathrm{ng} \mathrm{ml}^{-1}$ IFN $\gamma$ overnight prior to infection. Cell death $(\mathbf{c}, \mathbf{d}, \mathbf{f}-\mathbf{h}, \mathbf{j})$ was quantified by LDH release at $3.5 \mathrm{~h}$ post-infection unless noted and ATP-based cell viability (e) was measured $2 \mathrm{~h}$ post-electroporation; data are means (bars) of three individual replicates (circles). Data are pooled from two experiments (a) and representative of three independent experiments (b-i). For gel source data, see Supplementary Fig. 1. 


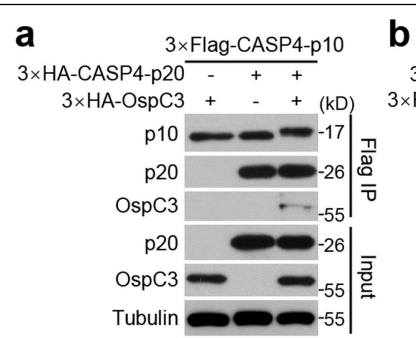

d
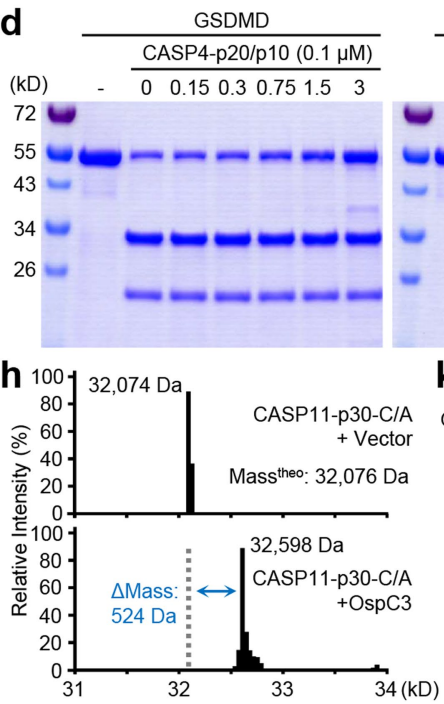

i

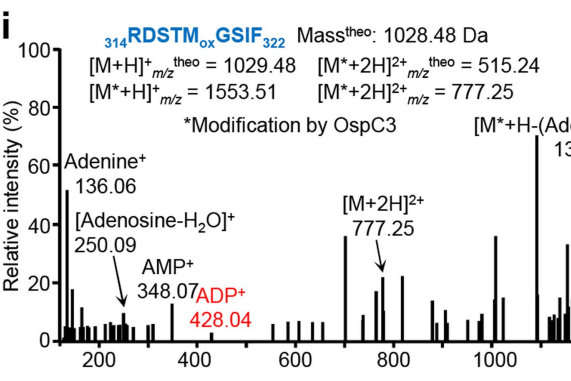

I

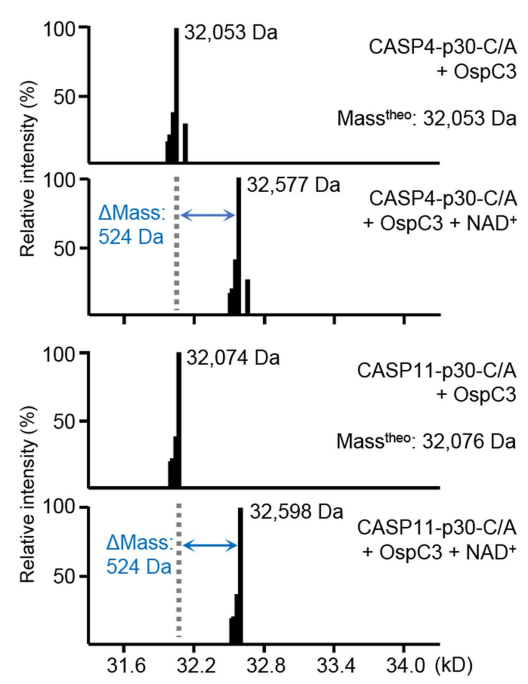

b $3 \times$ HA- CASP4- CASP11-C/A $3 \times$ Flag-RFP $\overline{+} \frac{\text { CASP11 }}{+-}$ Flag-OspC3 - + - + (kD) (kD) - - + OspC3

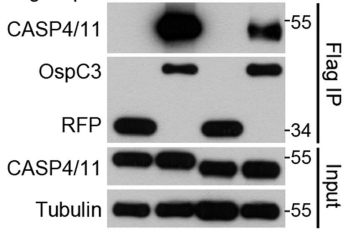

GSDMD

CASP11-p20/p10 (0.1 MM)

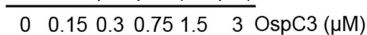

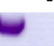

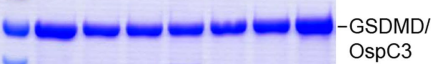

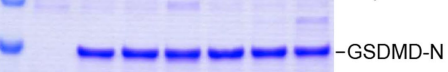

- - - - - GSDMD-C

k

CASP11-p30-C/A

NAD+ - + + 8
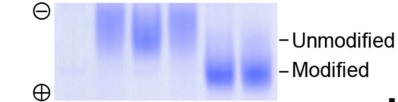

$\begin{array}{lcc}\mathrm{kD}_{55-} & \text { (Native-PAGE) } & \mathbf{j}\end{array}$

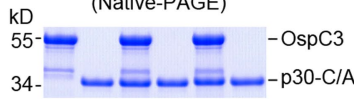

${ }_{100}$

e $\begin{array}{r}6 \times 10^{4} \\ \text { 于 } 5 \times 10^{4}\end{array}$

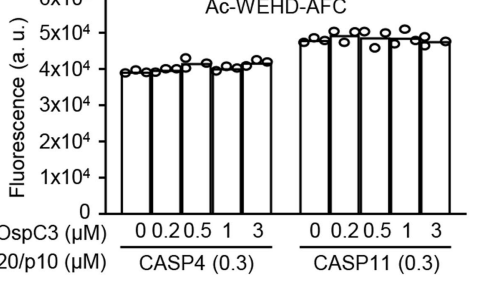

p20/p10 (HM) $\frac{\text { CASP4 (0.3) }}{\operatorname{CASP} 11(0.3)}$

g 100

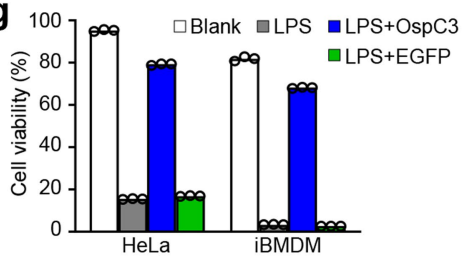

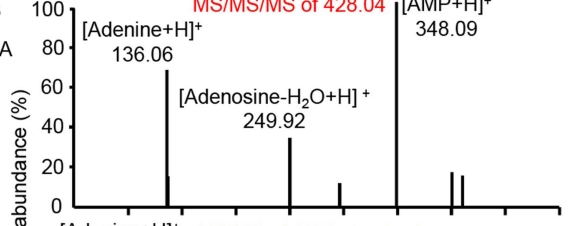

$\left[\mathrm{M}^{*}+\mathrm{H}\right]^{+}$

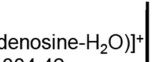

[Adenine $+\mathrm{H}^{+}$MS/MS of ADP standard

$\$$ [Aden 136.06 MS/MS of ADP standard 250.09

幽

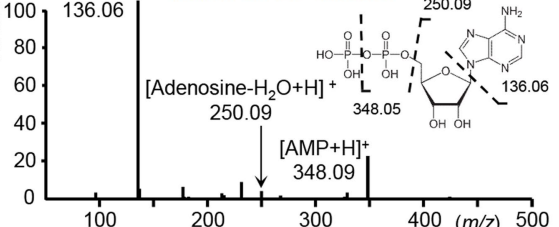

$400(\mathrm{~m} / \mathrm{z})$

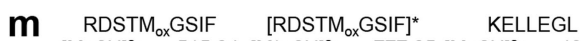

$[\mathrm{M}+2 \mathrm{H}]^{2+}{ }_{m / 2}=515.24\left[\mathrm{M}^{*}+2 \mathrm{H}\right]^{2+}{ }_{m / 2}=777.25[\mathrm{M}+2 \mathrm{H}]^{2+}{ }_{m / 2}=401.24$
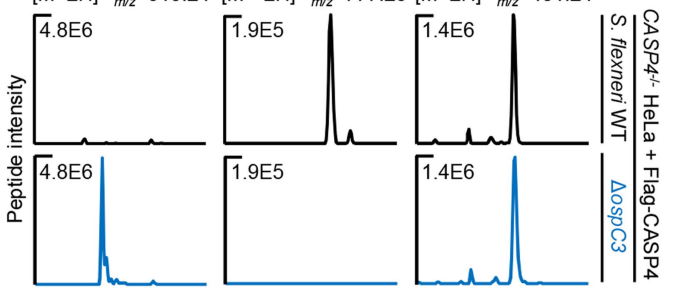

SYRDKTGGSY [SYRDKTGGSY] ${ }^{*}$ YSTTPHHL $\left.[\mathrm{M}+2 \mathrm{H}]^{2+}{ }_{\mathrm{m} / 2}=567.26\left[\mathrm{M}^{*}+2 \mathrm{H}\right]^{2+} \mathrm{m/2}=829.28[\mathrm{M}+2 \mathrm{H}]^{2+}\right]_{/ 2}=478.24$

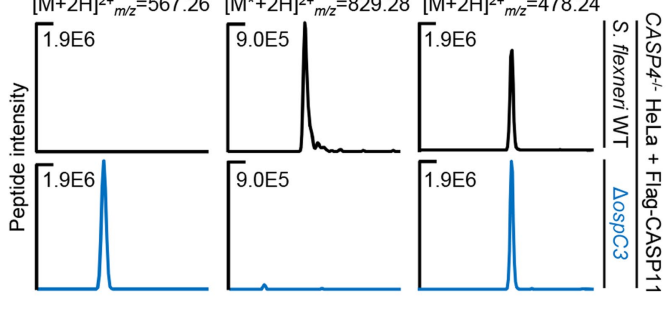

Extended Data Fig. 2 |See next page for caption. 


\section{Article}

Extended Data Fig. $2 \mid$ OspC 3 catalyzes an $\mathrm{NAD}^{+}$-dependent modification of caspase-4/11.a, b, Co-immunoprecipitation of OspC3 with caspase-4-p20/p10 (a) or full-length caspase-4/11 (b). C/A, the catalytic-cysteine mutant. c-e, GSDMD (c, d) or the fluorescent peptide substrate Ac-WEHD-AFC (e) were assayed for in vitro cleavage by caspase-4/11-p20/p10 in the presence of OspC3 at indicated concentrations. f, Cleavage of GSDMD by LPS-activated caspase- 4 in the presence or absence of OspC3. g, LPS alone or mixed with purified OspC3 or EGFP was electroporated into HeLa cells or iBMDMs. ATP-based cell viability was measured. h, k, Caspase-11-p30-C/A, expressed alone/with OspC3 in bacteria $(\mathbf{h})$ or reacted with $\mathrm{OspC} 3 \pm \mathrm{NAD}^{+}$in vitro $(\mathbf{k})$, was analysed by ESI-MS (h) or native/SDS-PAGE (k). Control, OspC3-modified caspase-11-p30-C/A. $\mathbf{i}, \mathbf{j}$, CID-tandem mass spectrum of a chymotryptic caspase- 4 peptide bearing the 524-Da modification. Purified caspase-4-p30-C/A, modified by OspC3 in E. coli, was subjected to mass spectrometry analyses.j, The upper and lower panels show the tandem mass spectra of a fragment ion $(m / z=428.04)$ from the modified peptide in i and the ADP standard, respectively. *, OspC3-modified; $\mathrm{M}_{\mathrm{ox}}$, oxidized methionine. I, ESI-MS determination of the molecular mass of caspase-4/11-p30-C/A that had been reacted with OspC3 in the presence or absence of NAD ${ }^{+} . \mathbf{m}$, EThcD-MS of purified caspase-4/11; extracted ion chromatograms of the R314/R310-containing peptides or a control peptide. *, OspC3-modified; $\mathrm{M}_{\mathrm{ox}}$, oxidized methionine. e, $\mathbf{g}$, Data are means (bars) of three individual replicates (circles). Data are representative of three (a-k) or two $(\mathbf{I}, \mathbf{m})$ independent experiments. For gel source data, see Supplementary Fig. 1. 


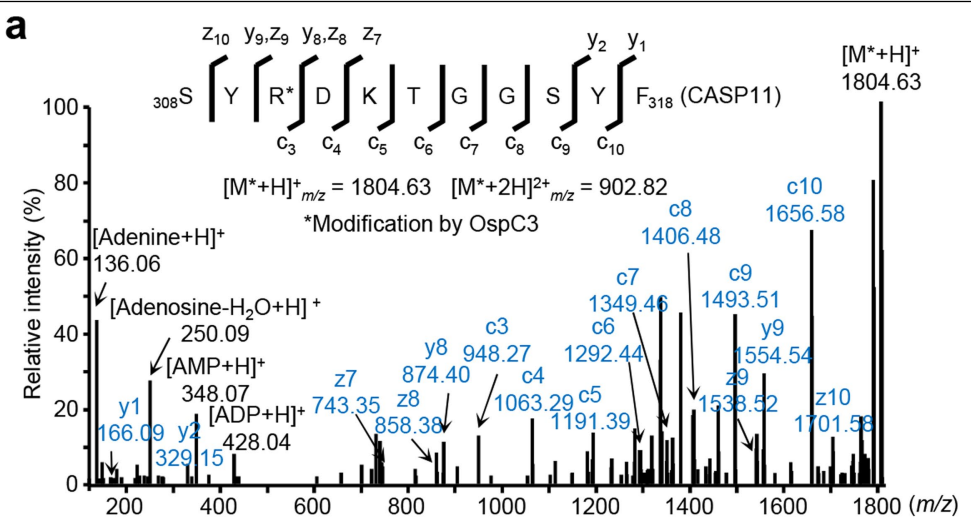

b
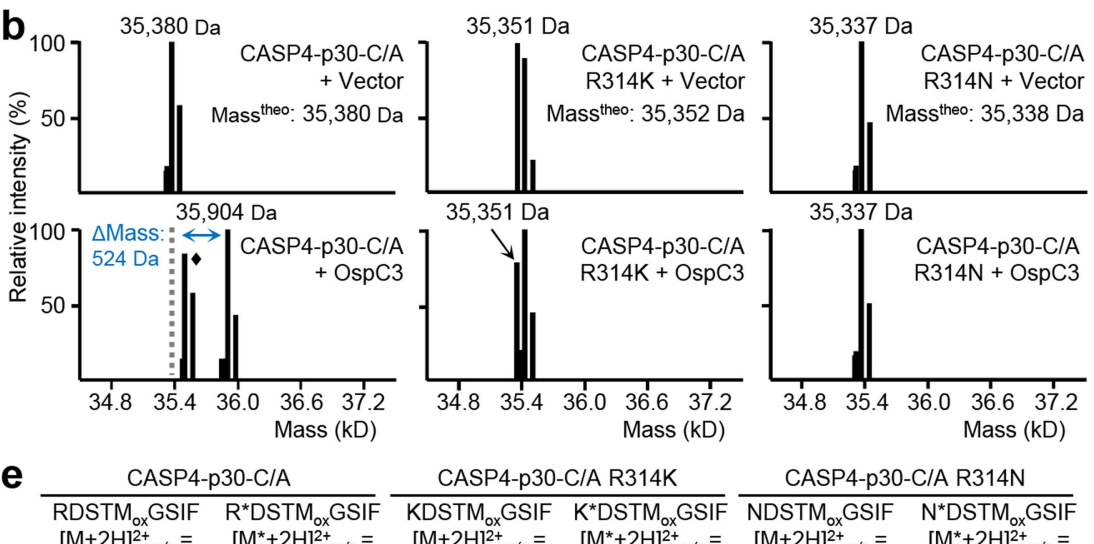$$
\text { d }
$$
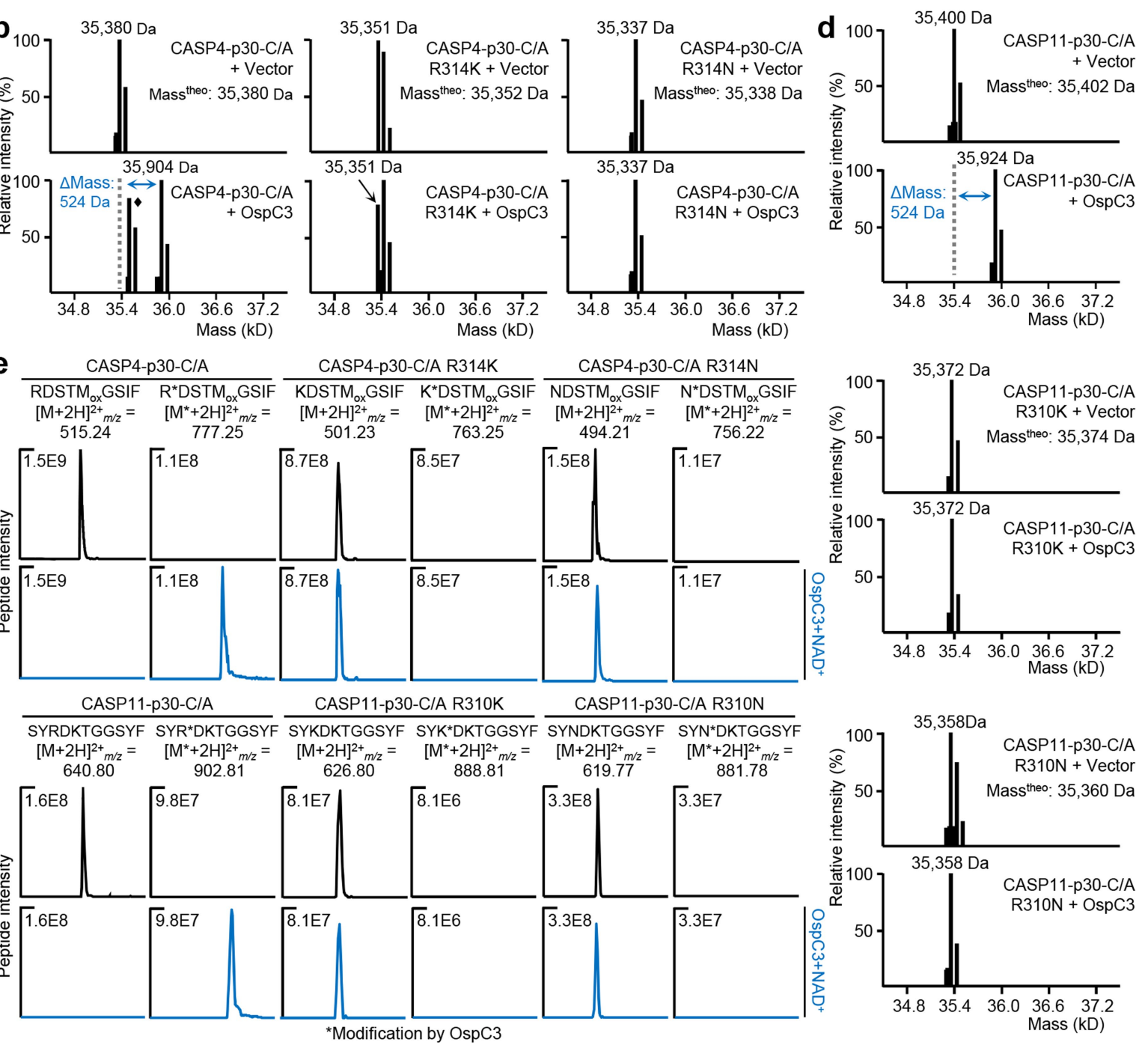

CASP11-p30-C/A R310N
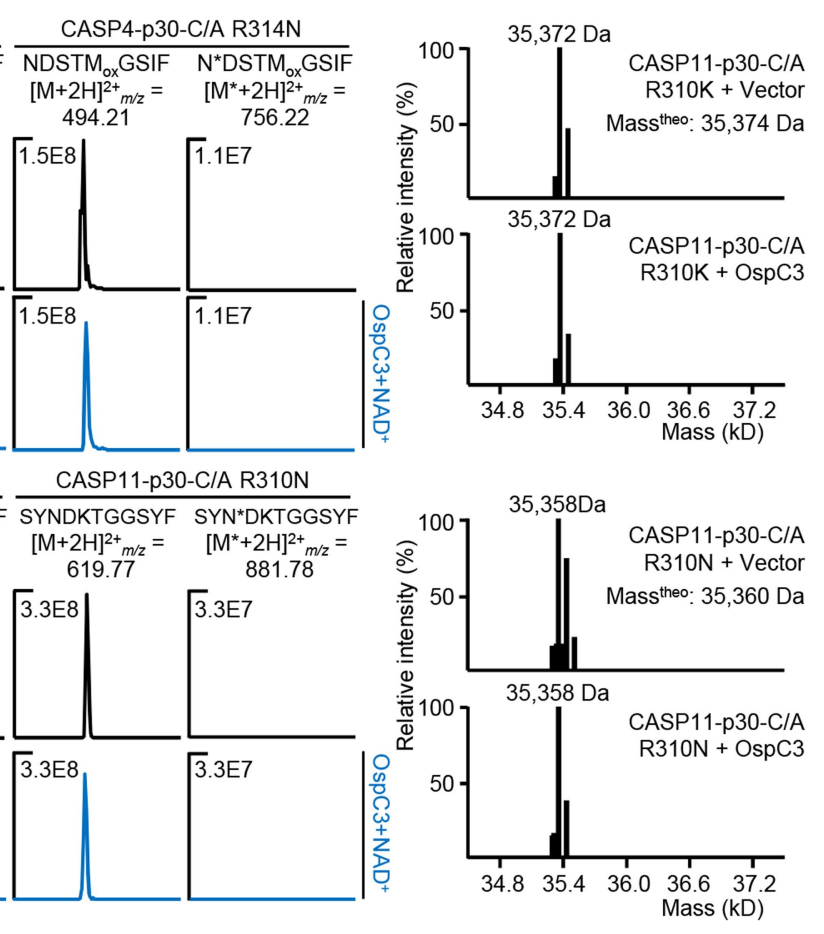

Extended Data Fig. 3 | OspC 3 modifies Arg314 in caspase-4 and the equivalent Arg310 in caspase-11. a, EThcD-tandem mass spectrum of the Arg310-containing chymotryptic peptide from modified caspase-11-p30-C/A obtained by co-expression with $\mathrm{OspC} 3$ in bacteria. Fragmentation patterns generating the observed $\mathrm{c} / \mathrm{z}$ and $\mathrm{b} / \mathrm{y}$ ions are indicated along the peptide sequence. b, d, Caspase-4/11-p30-C/A or an Arg314/R310 mutant were expressed alone or together with OspC3 in 293T cells. Immunopurified caspase-4/11-p30 were analysed by ESI-MS to determine the total molecular mass. , a contamination ion that only appeared in the particular experiment. c, e, Caspase-4/11-p30-C/A or an R314/R310 mutant protein were reacted with $\mathrm{OspC} 3$ in the presence or absence of $\mathrm{NAD}^{+}$. The reactions were analysed by native/SDS-PAGE (c). Chymotrypsin-digested caspase-4/11-p30 proteins were analysed by mass spectrometry (e). Shown are the extracted ion chromatograms of the R314/R310-containing peptides. a, e, $M_{o x}$, oxidized methionine. Data are representative of three $(\mathbf{a}, \mathbf{c}, \mathbf{e})$ or two $(\mathbf{b}, \mathbf{d})$ independent experiments. For gel source data, see Supplementary Fig. 1. 
a

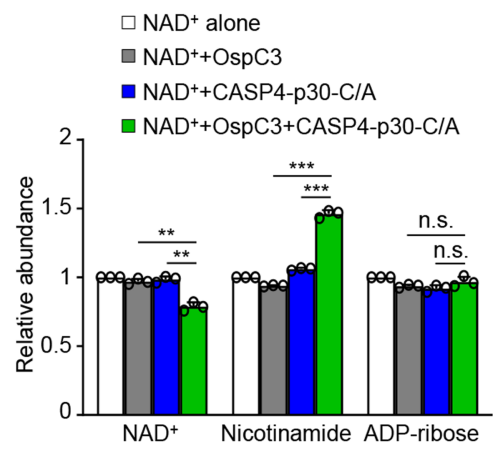

b

$\frac{\text { CASP4-p30-C/A }}{\text { OspC3 }}$

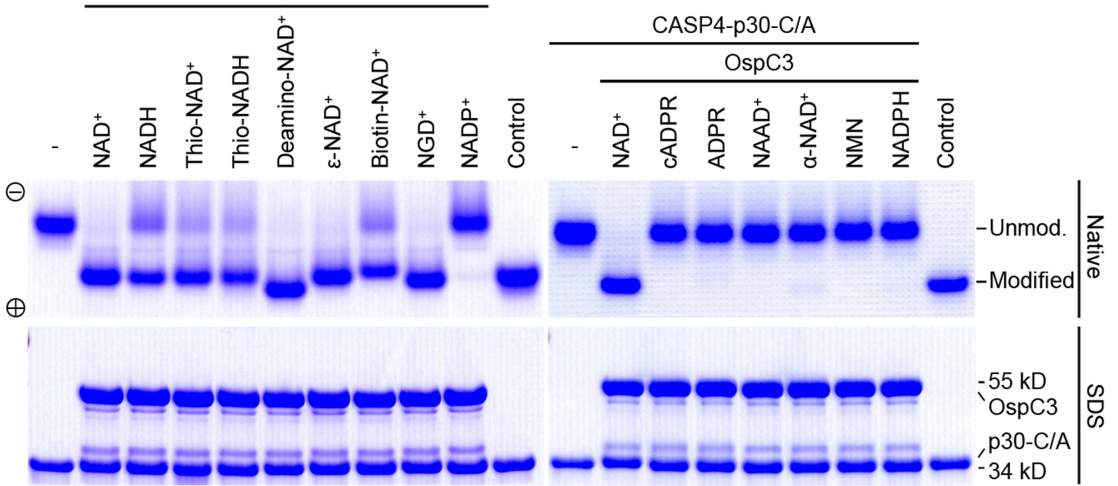

C

CASP4-p30-C/A+OspC3

*Modification by OspC3

\begin{tabular}{|c|c|c|c|c|c|c|}
\hline $\begin{array}{l}n^{*}+2 \mathrm{H}^{2} \\
769\end{array}$ & $\begin{array}{l}\mathrm{R}^{*} \mathrm{DSTMGSIF} \\
{\left[\mathrm{M}^{*}+2 \mathrm{H}\right]^{2+} \mathrm{m} / \mathrm{m}=}\end{array}$ & $\begin{array}{l}\mathrm{R}^{*} \text { DSTMGSIF } \\
{\left[\mathrm{M}^{*}+2 \mathrm{H}\right]^{2+} \mathrm{m} / \mathrm{z}}\end{array}$ & $\begin{array}{l}\mathrm{R}^{*} \text { DSTMGSIF } \\
{\left[\mathrm{M}^{*}+2 \mathrm{H}\right]^{2+}{ }^{2+} \mathrm{m/2}=}\end{array}$ & $\begin{array}{l}\mathrm{R}^{*} \text { DSTMGSIF } \\
{\left[\mathrm{M}^{*}+2 \mathrm{H}^{2+}\right]^{2+} \mathrm{m/z}=} \\
76975\end{array}$ & $\begin{array}{l}\mathrm{R}^{*} \text { DSTMGSIF } \\
{\left[\mathrm{M}^{*}+2 \mathrm{H}\right]^{2+} \mathrm{m} / \mathrm{z}} \\
781.26\end{array}$ & $\begin{array}{l}R^{*} \text { DSTMGSIF } \\
{\left[\mathrm{M}^{*}+2 \mathrm{H}\right]^{2+}{ }^{2+}{ }_{\text {m/z }}=} \\
960.36\end{array}$ \\
\hline
\end{tabular}
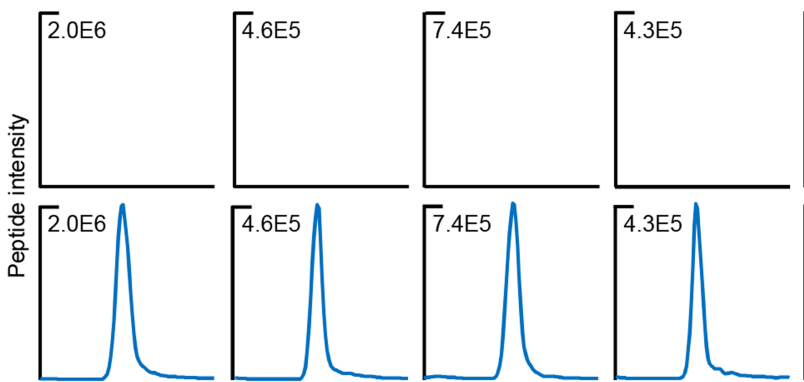

1

781.26

777.25 (1)
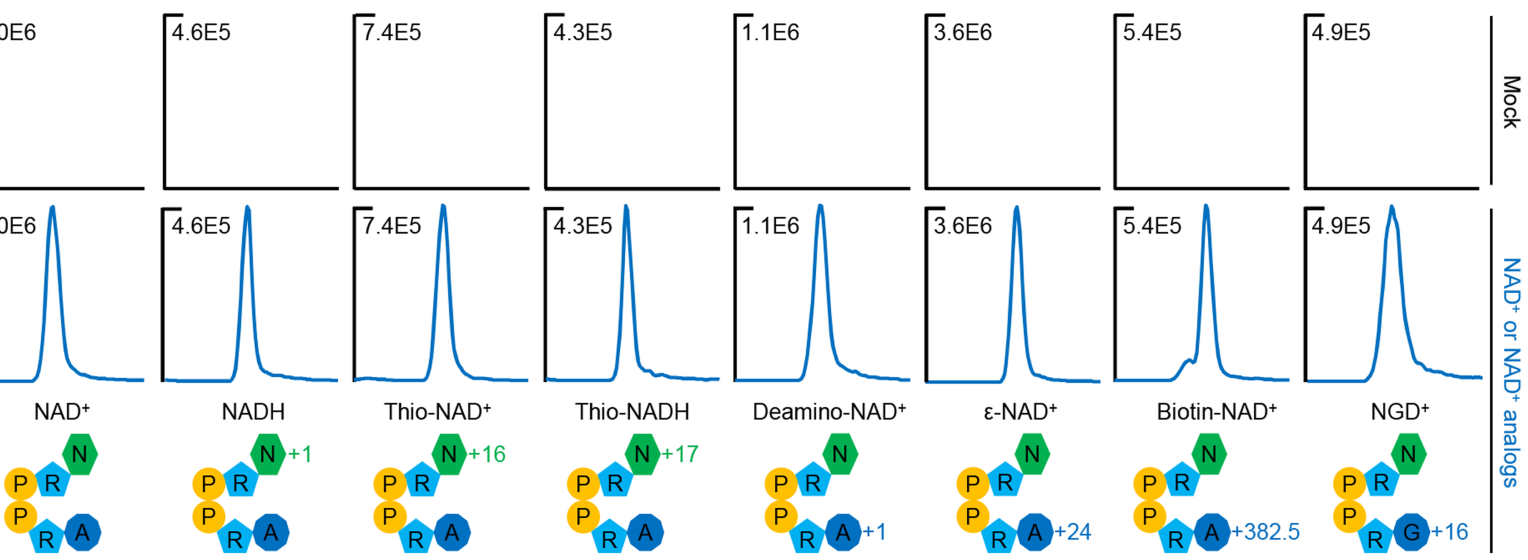

Deamino-NAD+

$\varepsilon-\mathrm{NAD}^{+}$
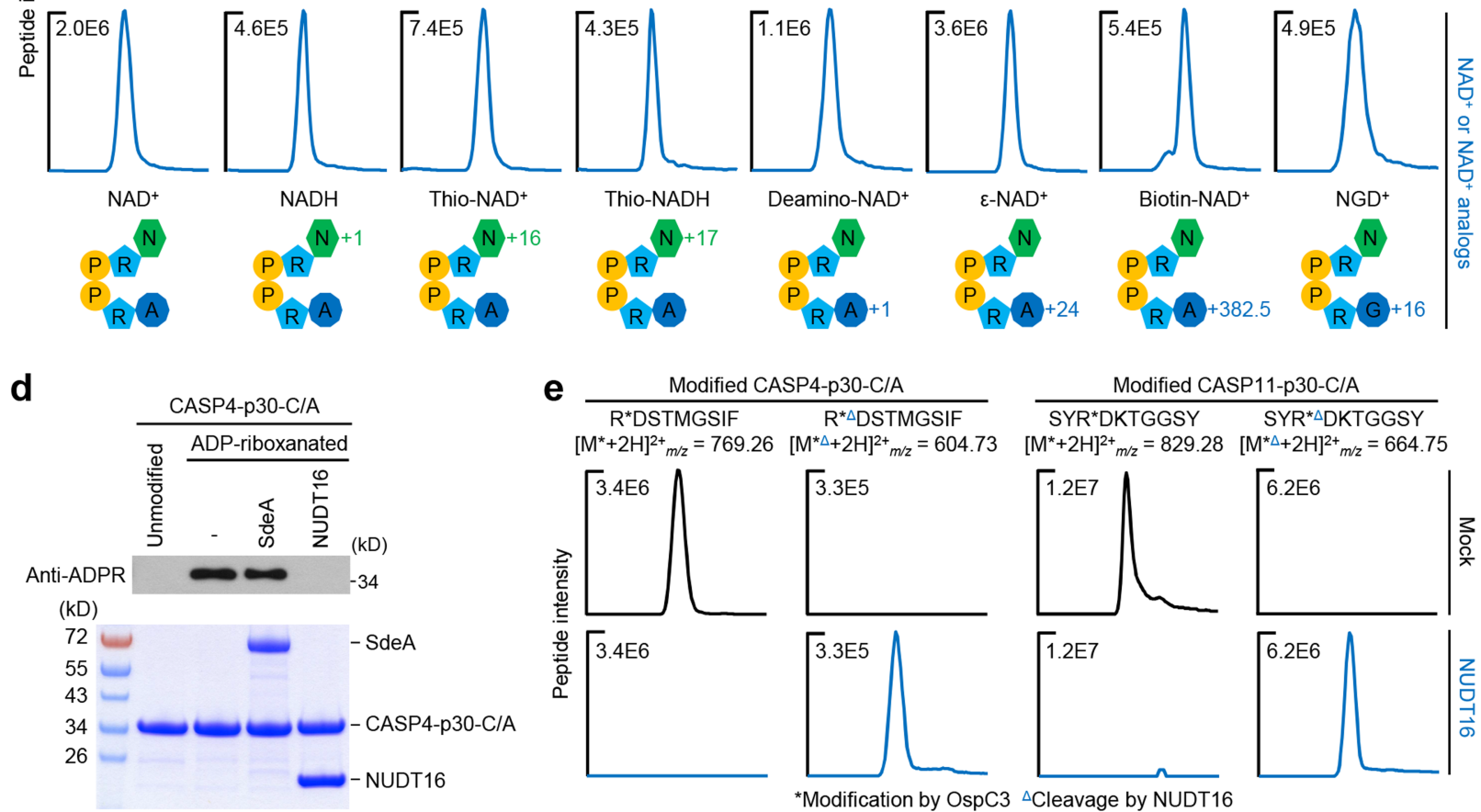

Extended Data Fig. $4 \mid$ OspC 3 modification of caspase-4/11 contains a step of ADP-ribosylation. a, HPLC-MS quantification of small-molecule products present in indicated in vitro caspase- 4 modification reactions. Mean values \pm s.d., $n=3$ (independent experiments), two-tailed unpaired Student's $t$-test $\left({ }^{* * *} P<0.001,{ }^{* *} P<0.01\right.$, ns, non-significant). b, c, Assessing the ability of various $\mathrm{NAD}^{+}$analogues or derivatives to support in vitro modification of caspase-4-p30-C/A by OspC3. b, The reactions were subjected to native/SDSPAGE analyses. Control, OspC3-modified caspase-4-p30-C/A in bacteria. c, Following the modification, caspase-4-p30 was digested with chymotrypsin and analysed by mass spectrometry. Shown are the extracted ion chromatograms of the R314-containing peptides. Mass changes of each analogue from $\mathrm{NAD}^{+}$are illustrated underneath the corresponding chromatograms. A, adenine; $\mathrm{N}$, nicotinamide; $\mathrm{P}$, phosphate; $\mathrm{R}$, ribose. d, e, Caspase-4/11-p30-C/A modified by OspC 3 in bacteria was treated with SdeA or NUDT16 overnight. d, The caspase- 4 samples were then immunoblotted with an anti-ADP-ribosylation antibody. e, Caspase-4/11 after NUDT16 treatment was digested with chymotrypsin and analysed by mass spectrometry. Shown are extracted ion chromatograms of the R314/R310containing peptides. All data are representative of three independent experiments. For gel source data, see Supplementary Fig. 1. 


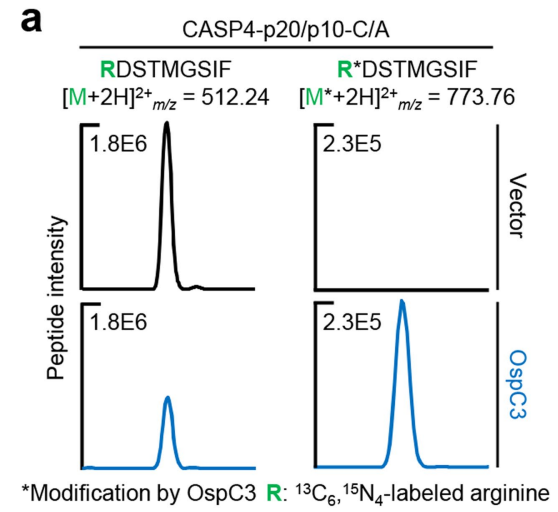

d<smiles>CN[C@@H](CCCNC(=N)[NH2+])C(=O)C(C)(C)C</smiles><smiles>O=C1c2ccccc2C(=O)C1(O)O</smiles>

Arginine residue Ninhydrin b

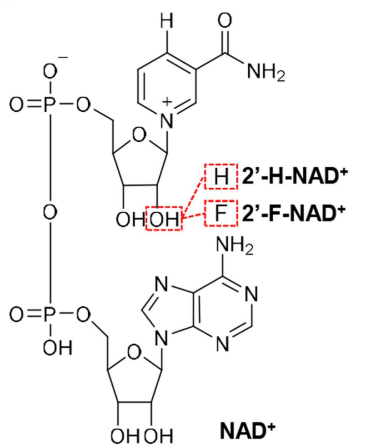

C CASP4-p30-C/A+OspC3 *Modification by OspC3

2'-H-NAD+ - Nam $\downarrow-\mathrm{NH}_{3}$ (theoretic) RDSTMGSIF R*DSTMGSIF R*DSTMGSIF $[\mathrm{M}+2 \mathrm{H}]^{2+}{ }_{\mathrm{m} / \mathrm{z}}=507.24\left[\mathrm{M}^{*}+2 \mathrm{H}\right]^{2+}{ }_{\mathrm{m} / \mathrm{z}}=769.77\left[\mathrm{M}^{*}+2 \mathrm{H}\right]^{2+}{ }_{\mathrm{m} / \mathrm{z}}=761.26$
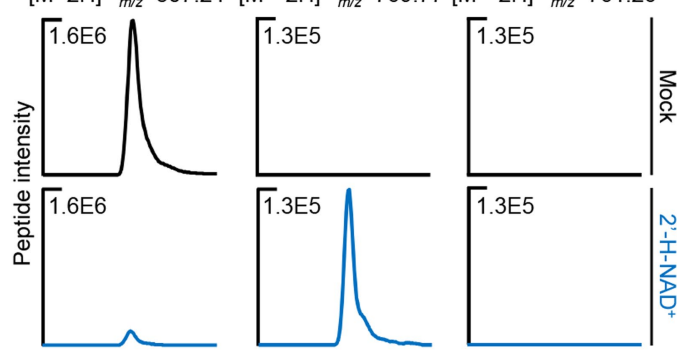

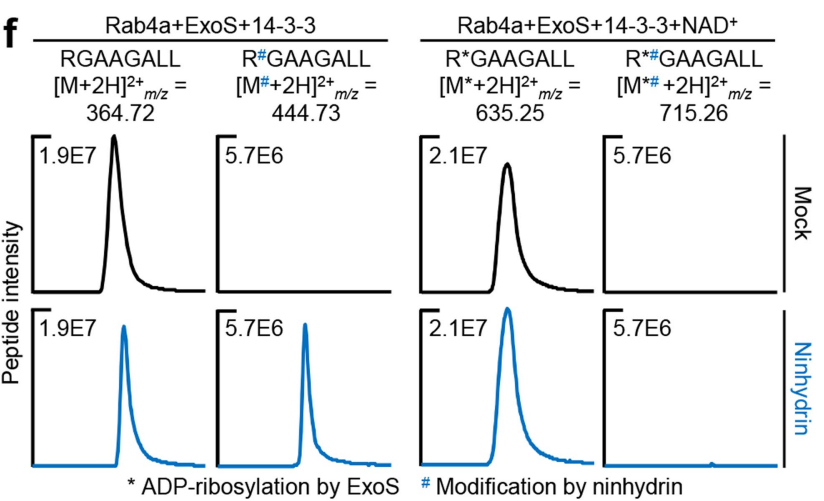

e Unmodified CASP4-p30-C/A
RDSTM $_{\text {ox }}$ GSIF $\quad$ R"DSTM
ox GSIF

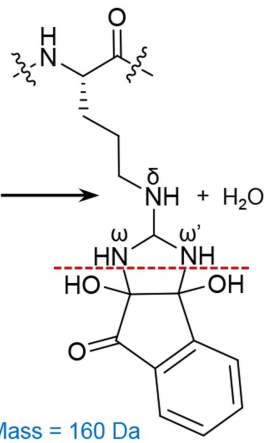

$\Delta$ Mass $=160 \mathrm{Da}$

*ADP-ribosylation by ExoS \# Modification by ninhydrin $[\mathrm{M}+2 \mathrm{H}]^{2+}{ }_{m / z}=515.24 \quad\left[\mathrm{M}^{\#+}+2 \mathrm{H}\right]^{2+}{ }_{m / z}=595.25$

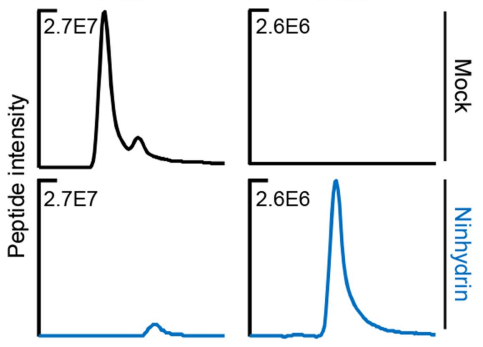

g

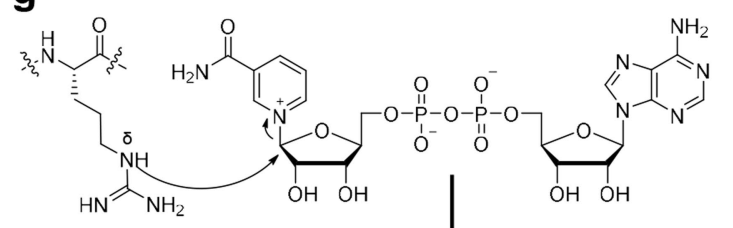

Step I: ADP-ribosylation of Arginine- $N_{\bar{\delta}}$<smiles>CC(=O)CC(C)(C)C</smiles>

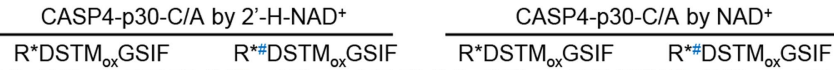
$\left[\mathrm{M}^{*}+2 \mathrm{H}\right]^{2+}{ }_{m / z}=777.77\left[\mathrm{M}^{\star *}+2 \mathrm{H}\right]^{2+}{ }_{m / z}=857.78\left[\mathrm{M}^{*}+2 \mathrm{H}^{2+}{ }_{m / 2}=777.25\left[\mathrm{M}^{*}+2 \mathrm{H}\right]^{2+}{ }_{m / 2}=857.26\right.$
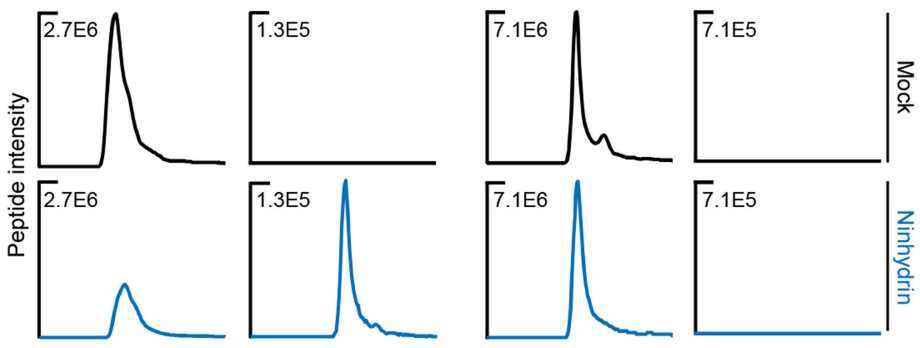

Extended Data Fig. 5 | OspC3-catalyzed modification involves ADP-ribosylation-dependent arginine deamination. a, Caspase-4-p20/ p10-C/A was expressed alone or co-expressed with OspC3 in 293T cells metabolically labeled with ${ }^{13} \mathrm{C}_{6},{ }^{15} \mathrm{~N}_{4}$-L arginine. Immunopurified caspase- 4 was analysed by mass spectrometry. b, Structural illustration of $2^{\prime}-\mathrm{H}^{-N A D^{+}}$and $2^{\prime}-\mathrm{F}_{-N A D}{ }^{+}$.c, Caspase-4-p30-C/A was reacted with OspC3 in the absence or presence of 2'-H-NAD ${ }^{+}$, and then analysed by mass spectrometry. d, Chemical scheme of ninhydrin modification of an arginine. e, Unmodified caspase4-p30-C/A or OspC3-modified caspase-4-p30-C/A using NAD ${ }^{+}$or 2'-H-NAD ${ }^{+}$ were incubated with $5 \mathrm{mM}$ ninhydrin for $8 \mathrm{~h}$ at room temperature, and then digested with chymotrypsin and analysed by mass spectrometry.f, Purified Rab4a was ADP-ribosylated by ExoS (activated by 14-3-3 protein). ADP-ribosylated and native Rab4a was incubated with $5 \mathrm{mM}$ ninhydrin, followed by mass spectrometry analyses. $g$, A proposed scheme of OspC3-catalyzed arginine ADP-riboxanation. a, c, e,f, Extracted ion chromatograms of caspase-4 R314-containing peptides (a, c, e) or Rab4a R84-containing peptide (f). Data are representative of two (a) or three (c, e,f) independent experiments. 
a

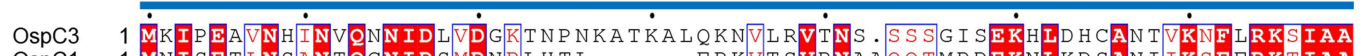

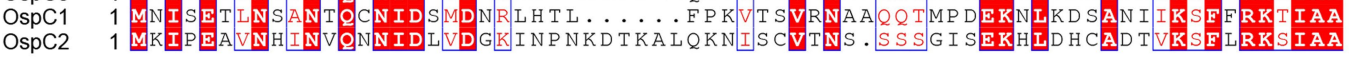

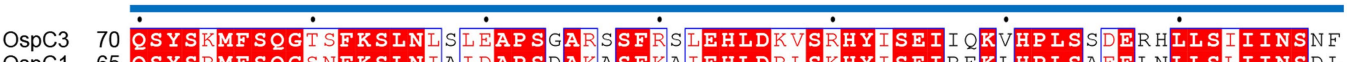

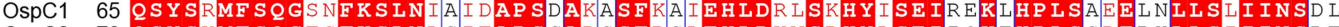

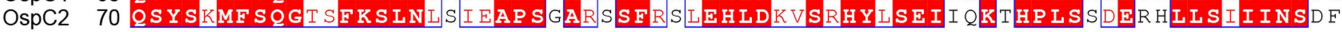

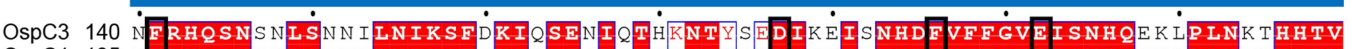
OspC1 135 IFRHOSNSDLSDK ILNIKSFNKIQSEGICTKRNTYADDIKKIANHDFVFFGVEISNHOKKHPLNTKHHTV

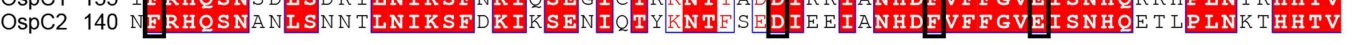

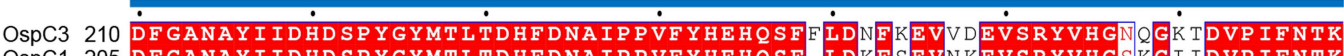
OspC1 205 DF GANAYI I DHD SPY GYMTLTDHF DNAIP PVFYHEHQSF. LDKE SEVNKEVSRYVHGSKGI IDVP IFNTK OspC2 210 DF GANAYI I DHD SPY GYMT L T DHF DNA I P PVF Y HEH SSFF LDNEKEVVDEV SRYVHGNQGK TDVP IFNTK

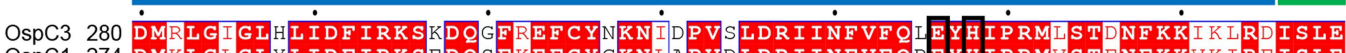
OspC1 274 DMKLGLGLYLIDF IRKSEDQSFKEFCYGKNLAPVDLDR I INFVF QPEYHIPRMVSTENFKKVK IREISLE OspC2 280 DMRLGIGLHLIDFIRKSKDQREREFCYNKNID PVSLDRI INFVEOLEYHIPRMISTDNFKKIRIRDISLI

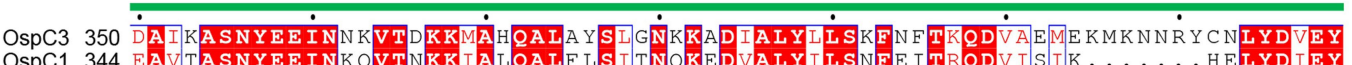

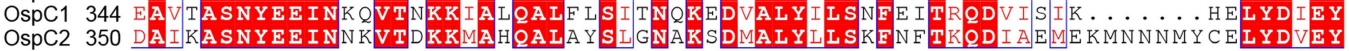

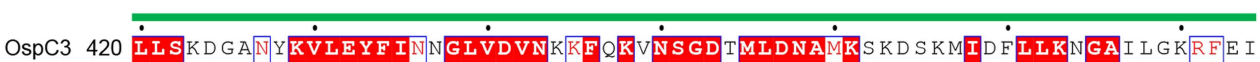
OspC1 407 L LSAHNS SCKVLEYFINKGLVDVNTKEKKTNSGDCMLDNAIKYENAEMIKLILKYGATSDNKYI. OspC2 420 LLSED SANYKVLEYF I SNGLVDVNKREOKANSGDTMLDNAMKSKDSKTIDFLLKNGAVSGKRFGR

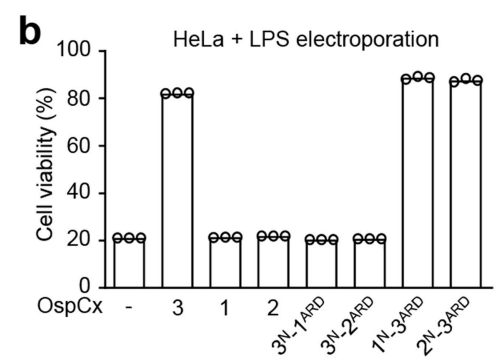

d

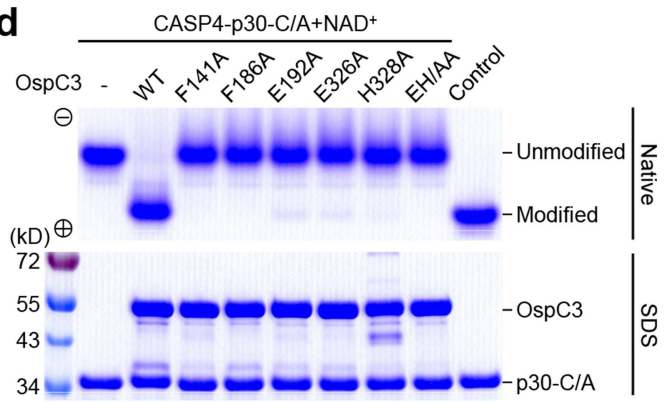

e

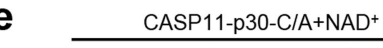

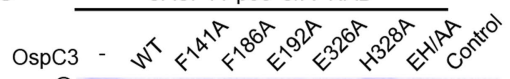

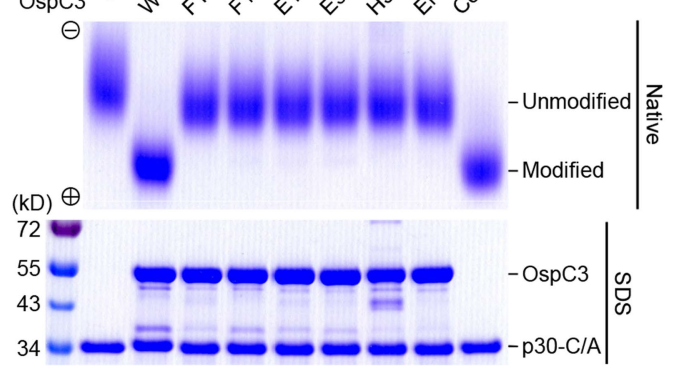

Ankyrin-repeat domain (ARD)

f ${ }_{45} \mathrm{SiHa}$ C $3 \times$ HA-CASP4-P30-C/A

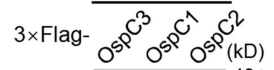
$\mathrm{P} 30-\mathrm{C} / \mathrm{A}=-{ }_{-55}^{-43} \mid \frac{\pi}{\overline{0}}$ $\mathrm{P} 30-\mathrm{C} / \mathrm{A}=\mathbf{m}^{-43}$ Tubulin $=-55$ 읃

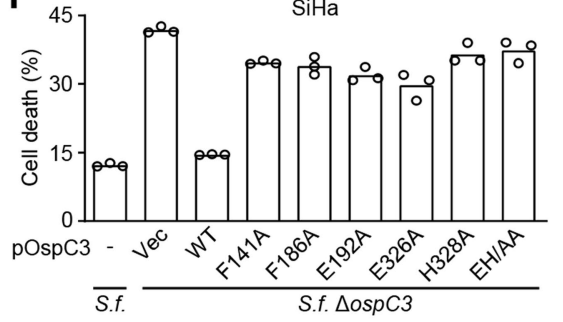

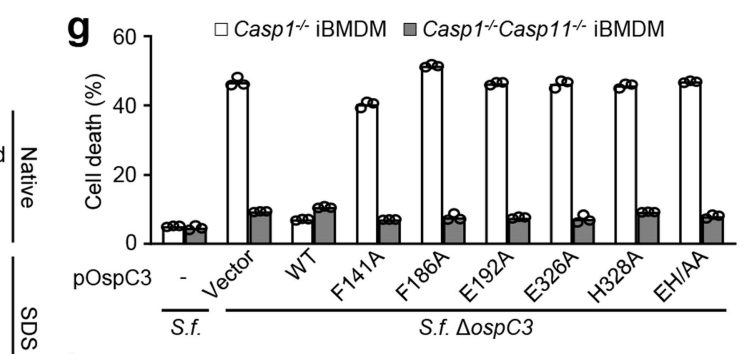

h CASP4-p30 modified by OspC3 WT D177A D231A Anti-ADPR

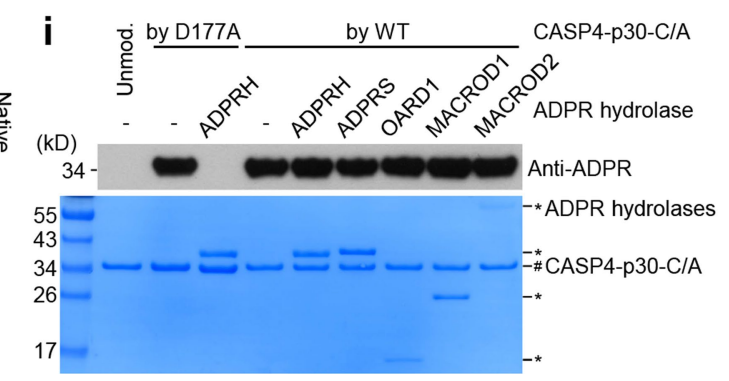

Extended Data Fig. 6 | See next page for caption. 
Extended Data Fig. 6 | Domain architecture and enzymatic properties of the OspC family. a, Multiple sequence alignment of OspC1, OspC2 and OspC3. The alignment was performed using the ClustalW2 algorithm and illustrated using ESPript 3.0 (http://espript.ibcp.fr/ESPript/cgi-bin/ESPript.cgi). Identical residues are in red background and conserved residues are colored in red. The $\mathrm{N}$-terminal putative ADP-riboxanase domain and the C-terminal ARD are marked along the sequence. Residues required for OspC3 ADP-riboxanase activity are highlighted by black rectangle. b. HeLa cells were electroporated with LPS together with recombinant OspC or an indicated chimeric protein. Cell viability was determined by the ATP assay. c, Co-immunoprecipitation of caspase-4-p30-C/A with an OspC-family member. d, e, Caspase-4/11-p30-C/A was reacted with $\mathrm{OspC} 3$ or an indicated mutant in the presence of $\mathrm{NAD}^{+}$. The reactions were subjected to native/SDS-PAGE analyses. Control, OspC3- modified caspase-11/4-p30-C/A in bacteria. EH/AA, OspC3 E326A/H328A. f, g, SiHa cells and Casp1 ${ }^{-/-}$or Casp1 $1^{-1-}$ Casp11 $1^{-1-}$ iBMDMs were infected with WT S.flexneri or an $\operatorname{ss} p C 3$ deletion/complementation strain. Cell death was measured by the LDH-release assay. $\mathbf{h}$, Flag-caspase-4-p30-C/A was coexpressed with OspC3 or an indicated mutant in 293T cells. i, Caspase-4-p30C/A was left unmodified (Unmod.) or pre-modified by OspC3 (WT or D177A) in vitro. Anti-Flag immunoprecipitates (h) or caspase-4-p30-C/A (i) were left untreated or treated with ADP-ribosylarginine hydrolase (ADPRH) or other indicated ADP-ribosylhydrolases. The samples were subjected to anti-ADPR immunoblotting. b, f, $\mathbf{g}$, Data are means (bars) of three individual replicates (circles). Data are representative of three (b-h) or two (i) independent experiments. For gel source data, see Supplementary Fig. 1. 


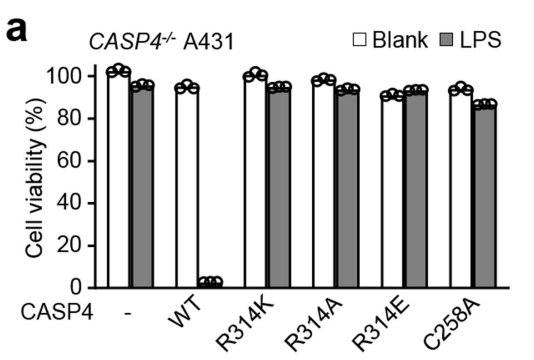

\section{b}
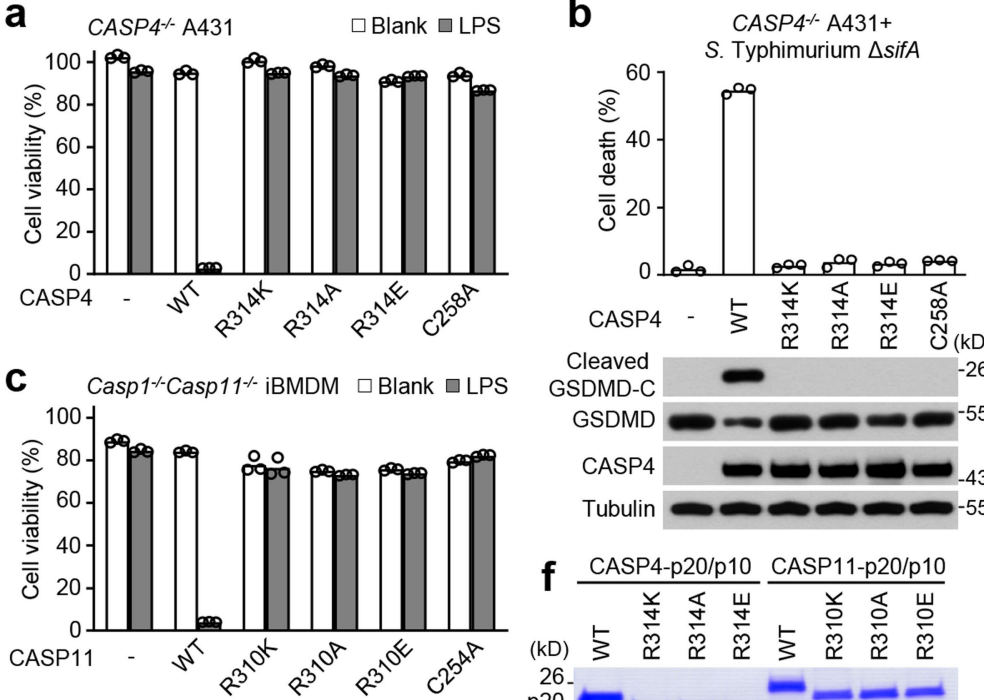

e

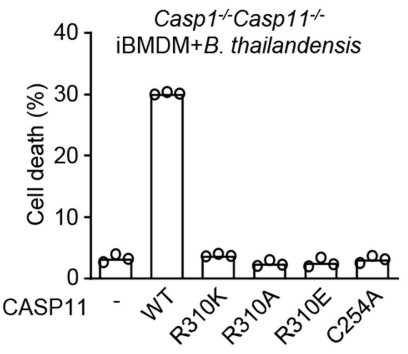

h

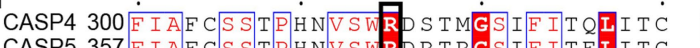
CASP5 357 F I A F C S S T P H NV S WRPR T R S I I I I T E I I T C CASP11 296 F I AF Y S T T P H H L S Y R KK T G G S Y F I T R I I S C CASP1 327 F I AFCSSTP DNVS WRHP TMGSVEIGRIIEH MCASP1 325FIAFCSSTPDNVSWRHPVRGSLFIESIIKH CASP2 364 M I CGYACIKG TA AMRNT KRGSWY IEALAQV CASP8 416 FLIGMATVNNCVSYRNPAETWYIQSICQS

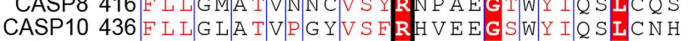
CASP9 341 I F VS Y S T F P G FV SWRPP K S SSWYVETTLDI CASP6 206 F LMCYSVAEGYYSHRETVNGSWY IQDLCEM CASP3 193 F L YAY S TAPG GY SWRN S KDGSWF I O S I CAM CASP7 219 FLFAYSTVEGYYSWRSP GRGSWEVQALC S I

Extended Data Fig. 7 | R314/R310 ADP-riboxanation of caspase-4/11 blocks their autoprocessing and also cleaving of GSDMD. a, c, $C A S P 4^{-1-}$ A431 cells (a) or Casp1 $^{-/-}$Casp11 $^{-/-}$iBMDMs (c) stably expressing an Arg314 or Arg310 mutant caspase- 4 or -11 , respectively, were electroporated with LPS. Cell viability was measured $2 \mathrm{~h}$ post-electroporation. b, d, e, $\mathrm{CASP}^{-/-} \mathrm{A} 431$ cells stably expressing caspase-4 (WT or an indicated R310 mutant) or Casp1 $^{1-}$ Casp11 $^{-1-}$ iBMDMs stably expressing caspase-11 (WT or an indicated R314 mutant) were infected with S. Typhimurium $\Delta$ sifA (b), or S. flexneri $\Delta o s p C 3$ (d) or B. thailandensis (e), respectively. Pyroptosis was measured by the LDH-release assay. b, d, Cell lysates were immunoblotted as shown and supernatants were blotted with the anti-cleaved GSDMD-C antibody. f, WT or R314/R310-mutant caspase-4/11-p20/p10 proteins were purified from bacteria and analysed by SDS-PAGE. g, Gel-filtration chromatography analyses of d
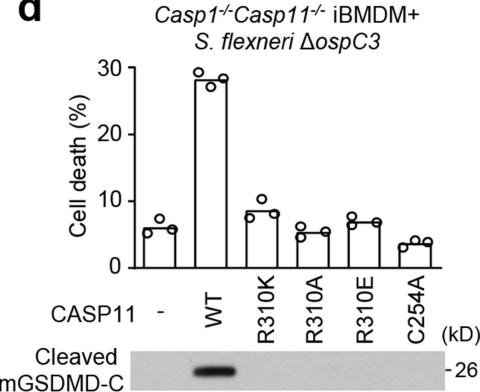

mGSDMD

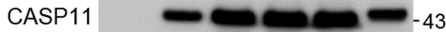

Tubulin

300 - CASP4-p20/p10+GSDMD-C

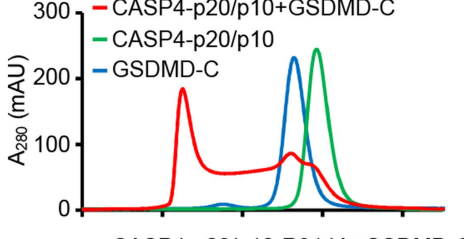

- CASP4-p20/p10-R314A+GSDMD-C

] - CASP4-p20/p10-R314A

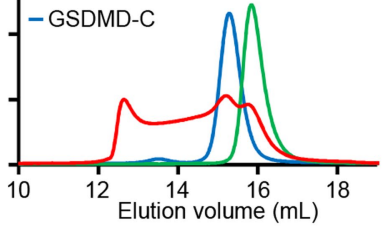

x104

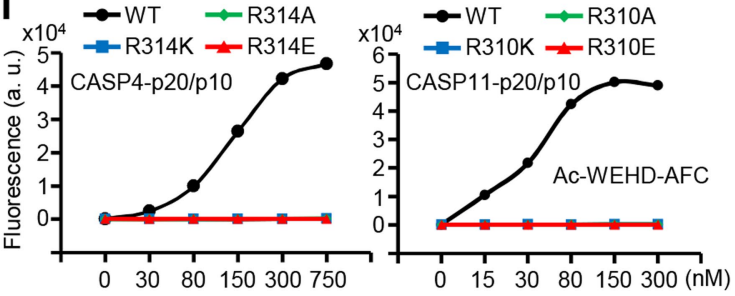

caspase-4-p20/p10 (WT or R314A)-GSDMD-C complex formation. Caspase4-p20/p10-A, R314-ADP-riboxanated form obtained by co-expression with OspC 3 in bacteria. $\mathbf{h}$, Alignment of caspase sequences around Arg314 in caspase-4. The alignment was performed using the ClustalW2 algorithm and presented using ESPript 3.0 (http://espript.ibcp.fr/ESPript/cgi-bin/ESPript. cgi). Identical residues are colored in red background and conserved residues are in red. The invariant arginine is highlighted by a black rectangle. Sequence numbers of the starting residues are indicated on the left. $\mathbf{i}$, Cleavage of the fluorescent peptide substrate Ac-WEHD-AFC by WT or R314/R310-mutant caspase-4/11-p20/p10 proteins at the indicated concentrations. a-e, Data are means (bars) of three individual replicates (circles). All data are representative of three independent experiments. For gel source data, see Supplementary Fig. 1. 


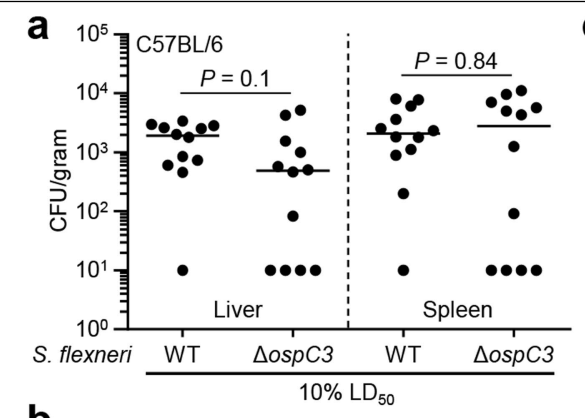

b
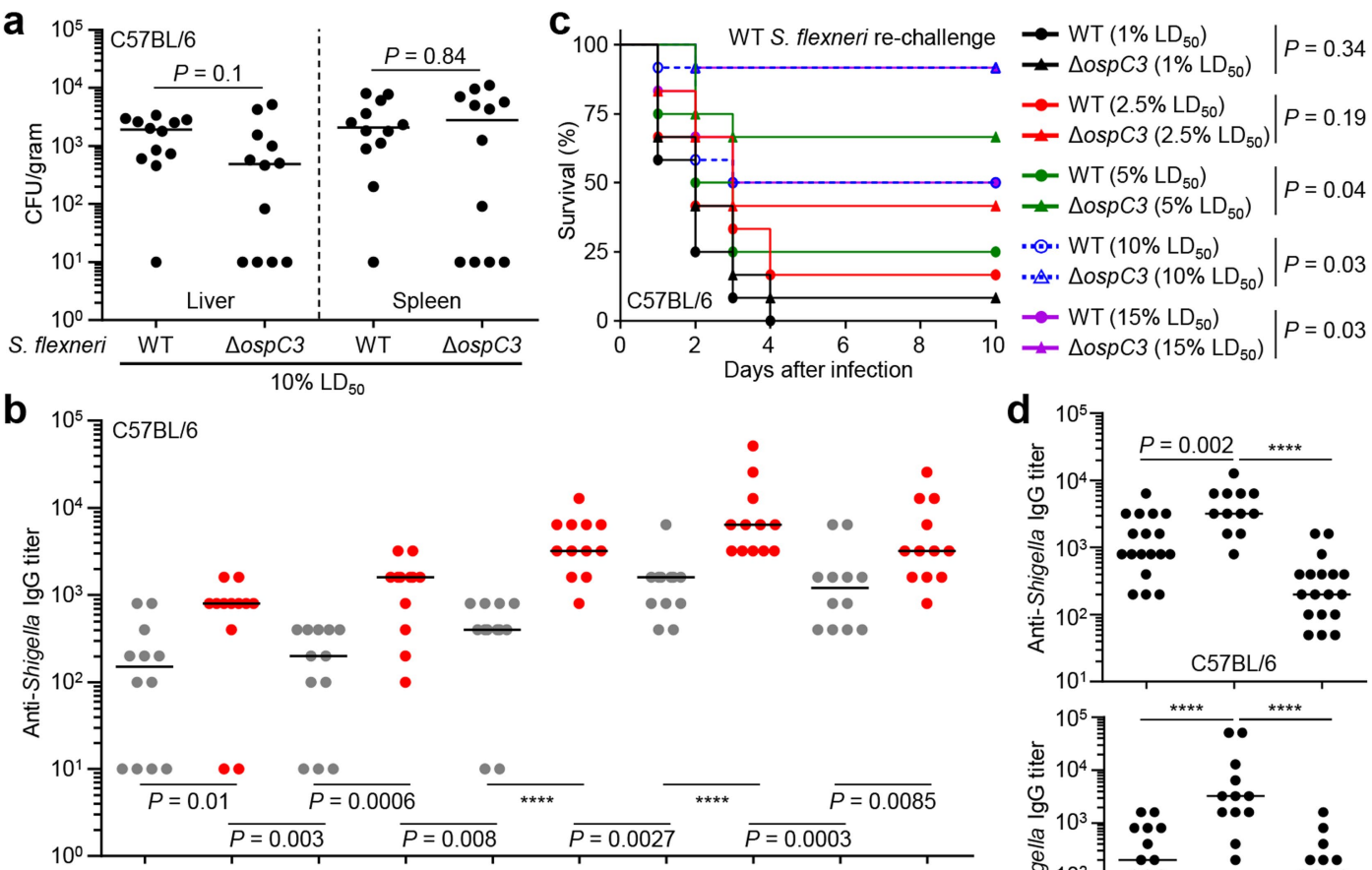

$\begin{array}{lllllll}\text { S. flexneri } & \frac{\mathrm{WT} \Delta \text { TospC3 }}{1 \% \mathrm{LD}_{50}} & \frac{\mathrm{WT} \Delta \text { ospC3 }}{2.5 \% \mathrm{LD}_{50}} & \frac{\mathrm{WT} \Delta \text { ospC3 }}{5 \% \mathrm{LD}_{50}} & \frac{\mathrm{WT} \Delta \text { ospC3 }}{10 \% \mathrm{LD}_{50}} & \frac{\mathrm{WT} \Delta \text { ospC3 }}{15 \% \mathrm{LD}_{50}}\end{array}$

e

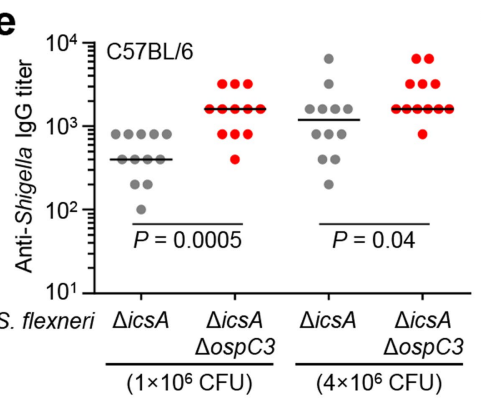

$f$

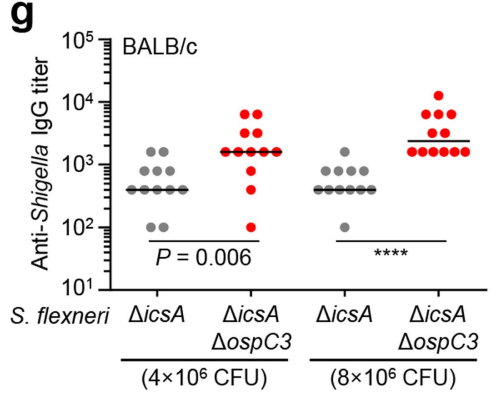

d 1
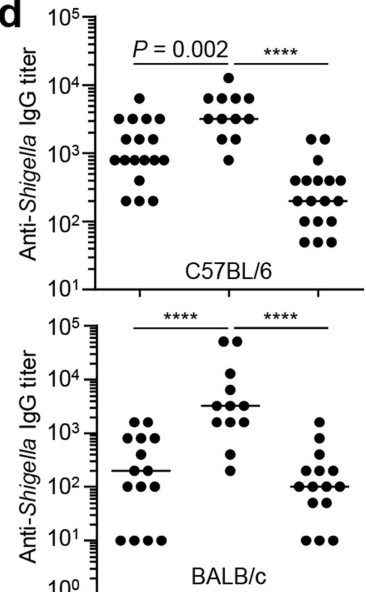

S. flexneri $\triangle i c s A \quad \triangle \circ \operatorname{spC} \triangle \mathrm{guaBA}$ $\left(2 \times 10^{6} \mathrm{CFU}\right)$

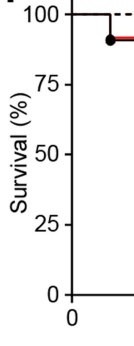

WT S. flexneri re-challenge

C57BL/6

h

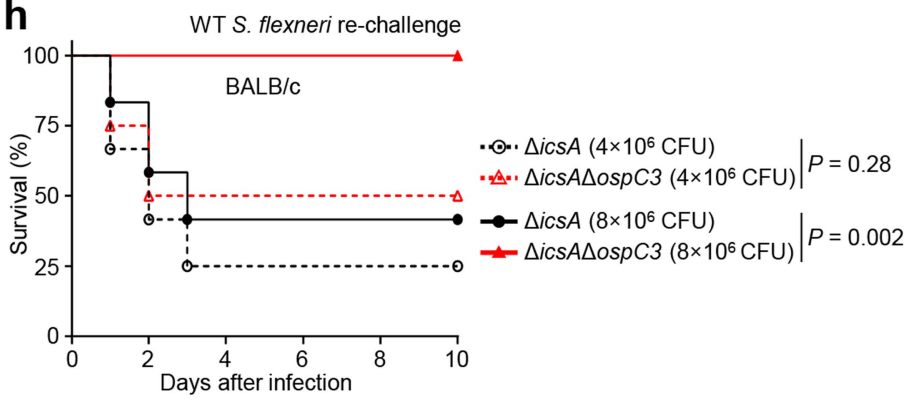


a

$$
\text { WP_015683184.1 }
$$

Enteroinvasive $E$. coli (EIEC) WP_046881740.1

Erwinia mallotivora WP_084276252.1 Vibrio pectenicida WP_125323138.1

Proteus cibarius WP_157954996.1

Providencia burhodogranariea
EKT62970.1 EKT62970.1 Vibrio alginolyticus
KOE80678.1 Vibrio aestuarianus
WP_172533069.1 lodobacter fluviatilis WP_130107019.1 Pantoea stewartii WP_006122225.1 Vibrio mediterranei WP_124942324.1 Yersinia massiliensis WP_072085332.1

Morganella morganii WP_186848843.1

$$
\text { Cedecea sp. }
$$

WP_172569927.1 Escherichia albertii

EFJ2288537.1 Pseudomonas fluorescens
WP_150781679.1 Citrobacter amalonaticus
WP_103774980.1 WP_103774980.1 Citrobacter amalonaticus WP_103774771.1 Erwinia tracheiphila AXF76402.1

Serratia marcescens WP 171404533.1 Burkholderia cepacia
WP_080970833.1

Burkholderia ubonensis WP_080417040.1 Chromobacterium violaceum WP_080762233.1 Chromobacterium violaceum WP_011135586.1

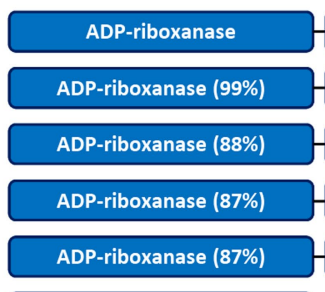

ARD

ARD (100\%)

ARD (78\%)

ARD (81\%)

ARD $(80 \%)$

ADP-riboxanase (85\%)

ARD (71\%)

ADP-riboxanase (84\%)

ADP-riboxanase (84\%)

ADP-riboxanase (84\%)

ADP-riboxanase (84\%)

ADP-riboxanase (83\%)

ADP-riboxanase (83\%)

ADP-riboxanase (82\%)

ADP-riboxanase $(82 \%)$

ADP-riboxanase (82\%)

ADP-riboxanase (81\%)

ADP-riboxanase (81\%)

ADP-riboxanase $(80 \%)$

ADP-riboxanase (78\%)

ADP-riboxanase $(77 \%)$

ADP-riboxanase (71\%)

ADP-riboxanase $(70 \%)$

ADP-riboxanase (70\%)

ADP-riboxanase (69\%)
Extended Data Fig. 9|The wide presence of OspC-like arginine ADP-riboxanase in bacteria. a, Domain organization of OspC homologs identified through BLAST searches. The source of bacterial species and the accession number of the homologs are indicated on the left of the diagram. Sequence similarity of each homolog to OspC3 within the ADP-riboxanase domain and the ARD are indicated. b, $C A S P 4^{-/-}$HeLa cells stably expressing Flag-caspase-4/11 were transfected with an indicated OspC3 homolog. LPS was electroporated into the cells and ATP-based cell viability was measured $2 \mathrm{~h}$ post-electroporation. Data are means (bars) of three individual replicates

b

C

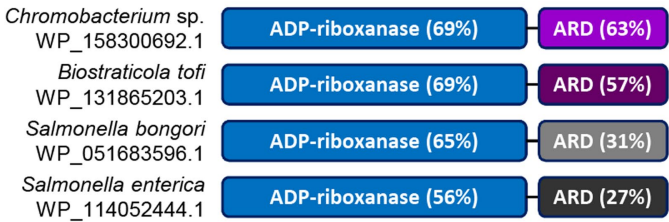

LPS electroporation
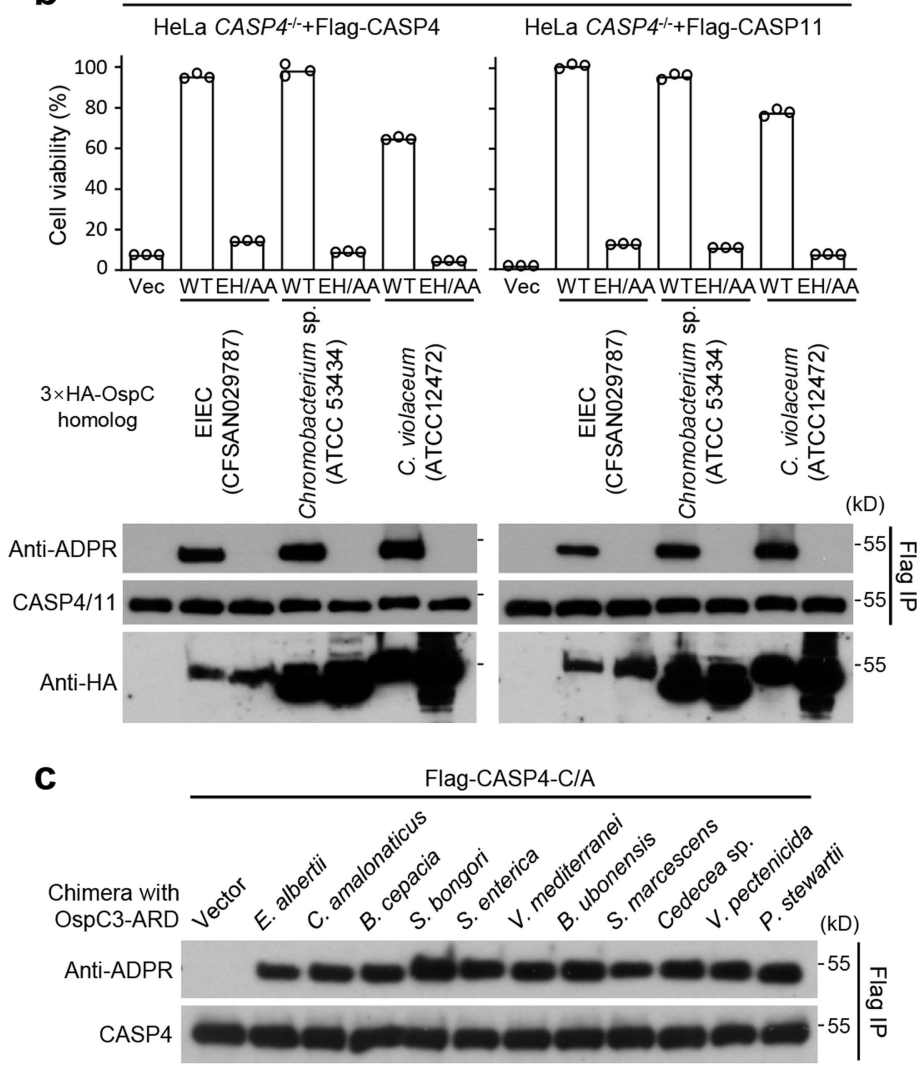

(circles). Cell lysates prepared prior to LPS electroporation were subjected to anti-Flag immunoprecipitation. EH/AA, mutations corresponding to the E326A/H328A double mutation in OspC3. c, Lysates of 293T cells co-transfected with Flag-caspase-4-C/A and a chimeric OspC-family protein (replacing the ARD with that of OspC3) were subjected to immunoprecipitation. The homolog from C. amalonaticus used is WP_103774980.1.b, c, Anti-Flag, anti-HA or anti-ADPR immunoblotting. Data are representative of two independent experiments. For gel source data, see Supplementary Fig. 1 . 

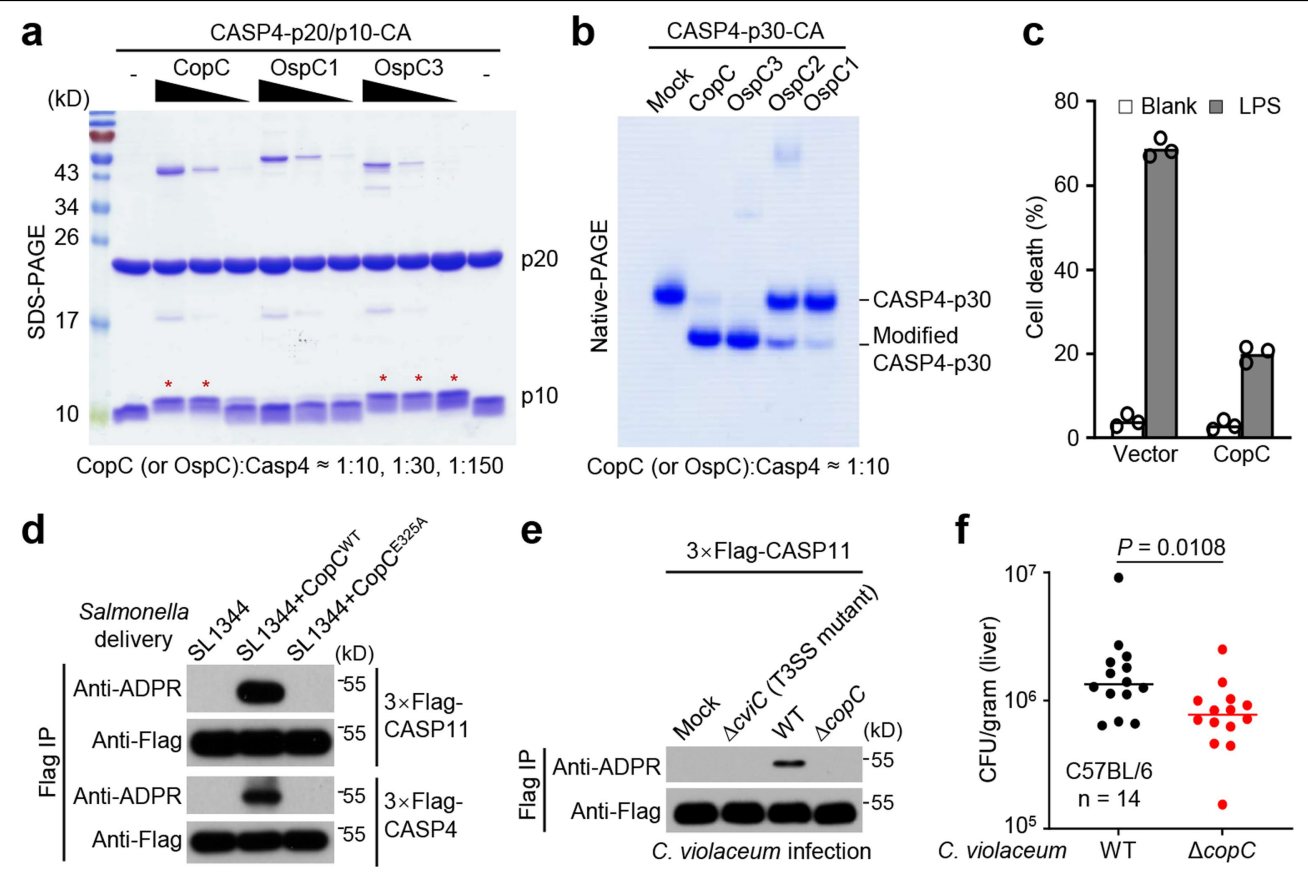

Extended Data Fig. 10 | Functional analyses of the CopC effector from C. violaceum. a, b, Purified caspase-4-p20/p10-C/A (a) or caspase-4-p30-C/A (b) was reacted with recombinant $\mathrm{CopC}$ or OspC protein (CopC $\triangle \mathrm{N} 50$ and OspC $3 \Delta \mathrm{N} 52$ were used in a) at the indicated molar ratio in the presence of $\mathrm{NAD}^{+}$. Reactions were analysed by SDS-PAGE (a) or native-PAGE (b). Red * indicates ADP-riboxanation of caspase-4-p10. c, HeLa cells expressing CopC or an empty vector were electroporated with LPS. Cell death was measured by the LDH-release assay. Data are means (bars) of three individual replicates (circles). d, e, 3xFlag-caspase-4/11-expressing 293T cells were infected with $S$.
Typhimurium SL1344 harboring CopC WT or E325A (d) or C. violaceum WT, $\triangle c v i C$ or $\triangle \operatorname{copC}(\mathbf{e})$. Immunoprecipitated Flag-caspase-4/11 was subjected to anti-Flag or anti-ADPR immunoblotting.f, C57BL/6 mice ( $n=14$ for each group) were intravenously infected with C. violaceum WT or $\Delta \operatorname{cop} C\left(5 \times 10^{3}\right.$

CFU per mouse). Seventy-two $h$ later, bacterial burden in the mouse liver (CFU per gram) was determined (median values, two-tailed Mann-Whitney $U$-test). Data are representative of three $(\mathbf{a}-\mathbf{c})$ or two $(\mathbf{d}-\mathbf{f})$ independent experiments. For gel source data, see Supplementary Fig. 1. 


\section{nature portfolio}

Corresponding author(s): Feng Shao

Last updated by author(s): Sep 1, 2021

\section{Reporting Summary}

Nature Portfolio wishes to improve the reproducibility of the work that we publish. This form provides structure for consistency and transparency in reporting. For further information on Nature Portfolio policies, see our Editorial Policies and the Editorial Policy Checklist.

\section{Statistics}

For all statistical analyses, confirm that the following items are present in the figure legend, table legend, main text, or Methods section.

n/a Confirmed

$\square$ The exact sample size $(n)$ for each experimental group/condition, given as a discrete number and unit of measurement

$\square$ A statement on whether measurements were taken from distinct samples or whether the same sample was measured repeatedly

$\square$ The statistical test(s) used AND whether they are one- or two-sided

Only common tests should be described solely by name; describe more complex techniques in the Methods section.

$\bigotimes$ A description of all covariates tested

Х $\square$ A description of any assumptions or corrections, such as tests of normality and adjustment for multiple comparisons

$\square$ A full description of the statistical parameters including central tendency (e.g. means) or other basic estimates (e.g. regression coefficient)

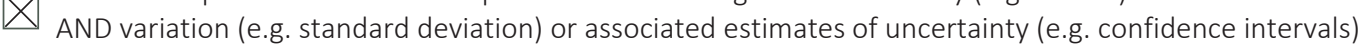

$\varnothing$ For null hypothesis testing, the test statistic (e.g. $F, t, r$ ) with confidence intervals, effect sizes, degrees of freedom and $P$ value noted

Give $P$ values as exact values whenever suitable.

Х $\square$ For Bayesian analysis, information on the choice of priors and Markov chain Monte Carlo settings

Х $\square$ For hierarchical and complex designs, identification of the appropriate level for tests and full reporting of outcomes

Х $\square$ Estimates of effect sizes (e.g. Cohen's $d$, Pearson's $r$ ), indicating how they were calculated

Our web collection on statistics for biologists contains articles on many of the points above.

\section{Software and code}

Policy information about availability of computer code

Data collection Not applicable

Data analysis Prism 6 (GraphPad Software Inc) was used for statistical analyses.

For manuscripts utilizing custom algorithms or software that are central to the research but not yet described in published literature, software must be made available to editors and reviewers. We strongly encourage code deposition in a community repository (e.g. GitHub). See the Nature Portfolio guidelines for submitting code \& software for further information.

\section{Data}

Policy information about availability of data

All manuscripts must include a data availability statement. This statement should provide the following information, where applicable:

- Accession codes, unique identifiers, or web links for publicly available datasets

- A description of any restrictions on data availability

- For clinical datasets or third party data, please ensure that the statement adheres to our policy 


\section{Field-specific reporting}

Please select the one below that is the best fit for your research. If you are not sure, read the appropriate sections before making your selection. $\bigotimes$ Life sciences $\quad \square$ Behavioural \& social sciences $\quad \square$ Ecological, evolutionary \& environmental sciences

For a reference copy of the document with all sections, see nature.com/documents/nr-reporting-summary-flat.pdf

\section{Life sciences study design}

All studies must disclose on these points even when the disclosure is negative.

Sample size

No statistical methods were used to predetermine the sample sizes. Indeed, it is impossible to calculate the required sample size as the exact magnitude of experimental variation between animals can not be predicted from our current knowledge. The group sizes (at least five animals per group) exceed the minimum number of animals needed to reach statistical significance $(p<0.05)$ between experimental groups; such practice has been widely accepted in the field and also followed in our own previous publications (Li et al, Nature 2013; Wang et al, Nature 2017; Li et al, Nature 2017). To account for potential greater variability, more than 10 mice for each experimental group were analyzed in the current study. Independent repeats during the course of this study have also validated the accountability of the sample size chosen in our study.

Data exclusions There were no data exclusions.

Replication All experiments have been repeated for at least three times to ensure reproducibility, which is the general practice in our lab. All attempts at replication in this study are successful. Experiments results were robust and reproducible. The difference between the experimental group and the control group was statistically significant in the repetitive experiments.

Randomization No randomization was used in this study. For all in vivo experiments, animals were randomly assigned into an infection group. Other experiments are all standard cell culture and in vitro protein biochemical assays, and therefore randomization is not relevant.

Blinding No blinding was done in this study. Most of the experiments contained multiple steps (preparation of different bacterial strains, mouse infections, and so on) and scientists must keep careful track of conditions. It would be exceedingly difficult to blind such studies.

\section{Reporting for specific materials, systems and methods}

We require information from authors about some types of materials, experimental systems and methods used in many studies. Here, indicate whether each material, system or method listed is relevant to your study. If you are not sure if a list item applies to your research, read the appropriate section before selecting a response.

Materials \& experimental systems Methods

n/a Involved in the study

$\bigotimes$ Antibodies

$\bigotimes$ Eukaryotic cell lines

$\bigotimes \square$ Palaeontology and archaeology

$\mathrm{n} / \mathrm{a}$ Involved in the study

Х $\square$ ChIP-seq

\ $\square$ Flow cytometry

$\square$ Animals and other organisms

$\bigotimes \mid \square$ MRI-based neuroimaging

$\bigotimes \square$ Human research participants

\ $\square$ Clinical data

$\bigotimes \square$ Dual use research of concern

\section{Antibodies}

Antibodies used

Monoclonal antibodies for human GSDMD (ab210070/EPR19829), mouse GSDMD (ab219800/EPR20859), human cleaved GSDMD-C domain (ab227821/EPR20885-203), mouse cleaved GSDMD-C domain (ab255603/EPR20859-147) were from Abcam. Antibodies for Flag (F3165/M2 \& F7425/polyclonal) and tubulin (T5168/B-5-1-2) were from Sigma-Aldrich. The anti-HA antibody (3724/C29F4) was from Cell Signaling Technology, and rabbit Fc-fused mono-ADP-ribose binding reagent (MABE1076) was from Sigma-Aldrich. Monoclonal antibody for caspase-4 and polyclonal antibody for caspase-11 were generated by the in-house facility of National Institute of Biological Sciences, Beijing (NIBS). For western blot, HRP-conjugated anti-mouse IgG (NA931/polyclonal) and HRPconjugated anti-rabbit IgG (NA934/polyclonal) were purchased from GE Healthcare Life Sciences. For ELISA, HRP-conjugated goat anti-mouse IgG (1036-05/polyclonal) was purchased from SouthernBiotech (Lot: D4913-WJ86H). Antibodies for Flag and tubulin were used at 1:5000 dilution and all other primary antibodies were used at 1:1000 dilution for western blot. Secondary antibodies were used at 1:5000 and 1:6000 dilutions for western blot and ELISA, respectively.

Validation All the primary antibodies used were validated by the manufacturer or by ourselves with negative controls or knockout cell lysates to ensure good specificity. 
Policy information about cell lines

Cell line source(s)

HeLa, SiHa, A431, and 293T cells were obtained from the American Type Culture Collection (ATCC). Mouse immortalized bone marrow-derived macrophage (BMDM) cells were used frequently in our previous recent publications such as Reference 1. The cells were originally obtained from Dr. Katherine Fitzgerald's lab at University of Massachusetts Medical School and the original reference describing the cell line is PMID: 18604214.

Authentication

Identity of the cell lines were frequently checked by their morphological features but have not been authenticated by the short tandem repeat (STR) profiling.

Mycoplasma contamination

All cell lines were tested to be mycoplasma-negative by the standard PCR method.

Commonly misidentified lines

(See ICLAC register)

No commonly misidentified cell lines are used in this study.

\section{Animals and other organisms}

Policy information about studies involving animals; ARRIVE guidelines recommended for reporting animal research

Laboratory animals

8-10 week-old female mice (C57BL/6 or BALB/c background) were used for S. flexneri infection and immunization experiments described in this study. For infection of C. violaceum, 7-week-old female C57BL/6 mice were used.

Wild animals

No wild animals were used in this study.

Field-collected samples

No field-collected samples were involved in this study.

Ethics oversight

All mice were maintained in the specific pathogen-free facility at NIBS under standard housing conditions in accordance with the national guidelines for housing and care of laboratory animals (National Health Commission, China). The protocols for mouse experiments are in accordance with institutional regulations after review and approval by the Institutional Animal Care and Use Committee of NIBS.

Note that full information on the approval of the study protocol must also be provided in the manuscript. 